Article (refereed)

Cape, J.N. 2009 The use of passive diffusion tubes for measuring concentrations of nitrogen dioxide in air. Critical Reviews in Analytical Chemistry, 39 (4). 289-310. $\underline{10.1080 / 10408340903001375}$

(C) 2009 Taylor \& Francis Group

This version available http://nora.nerc.ac.uk/8362/

NERC has developed NORA to enable users to access research outputs wholly or partially funded by NERC. Copyright and other rights for material on this site are retained by the authors and/or other rights owners. Users should read the terms and conditions of use of this material at http://nora.nerc.ac.uk/policies.html\#access

This document is the author's final manuscript version of the journal article, incorporating any revisions agreed during the peer review process. Some differences between this and the publisher's version remain. You are advised to consult the publisher's version if you wish to cite from this article.

This is an electronic version of an article published in Critical Reviews in Analytical Chemistry, 39 (4). 289-310.

Critical Reviews in Analytical Chemistry is available online at: http://www.informaworld.com/smpp/ 


\title{
The use of passive diffusion tubes for measuring concentrations of nitrogen dioxide in air.
}

\author{
J. N. Cape \\ Centre for Ecology and Hydrology (Edinburgh Research Station) \\ Bush Estate, Penicuik, Midlothian, EH26 0QB, UK. \\ jnc@ceh.ac.uk
}

\begin{abstract}
Passive diffusion tubes have been widely used in Europe for spatial and temporal measurement of $\mathrm{NO}_{2}$ concentrations. The method is cheap, simple, and provides concentration data in most circumstances that are sufficiently accurate for assessing exposure and compliance with Air Quality criteria. Tube-type diffusion samplers are prone to several sources of uncertainty, arising from the materials of construction, the absorbent used, the methods of preparation, the details of their deployment (including the exposure time) and the analytical methods used to establish the concentration of nitrite ion absorbed. This review considers the major sources of uncertainty, and reports on the many experiments aimed at identifying and minimising uncertainties, including modifications to the simple open tube devices that were originally developed in the 1970s.
\end{abstract}

\section{Key words}

Passive sampling; $\mathrm{NO}_{2}$; nitrogen oxides; triethanolamine; Palmes tube 


\section{Introduction}

Since their introduction in the late 1970s for measuring personal exposure to nitrogen dioxide $\left(\mathrm{NO}_{2}\right)(1)$, passive diffusion tubes have been used as an inexpensive method for sampling $\mathrm{NO}_{2}$ concentrations in air over periods from a few days to a few weeks. Their main advantages are the lack of requirement for electrical power, the low cost of the materials, the simplicity of the analytical procedure, and the provision of an absolute air concentration that (in principle) does not require calibration.

The use of passive diffusion tubes for air sampling, in the workplace, in homes, as a personal sampler, or outdoors, is not restricted to $\mathrm{NO}_{2}$ but has been applied to a wide range of organic and inorganic gases (2-6). For $\mathrm{NO}_{2}$ the major issues concerning the use of Palmes-type passive diffusion samplers were reviewed over a decade ago (7), and although some of the problems identified have been more fully explored since then (8), there remain several issues that are of concern to regulatory and other agencies who wish a simple, cheap yet effective method for measuring time-averaged $\mathrm{NO}_{2}$ concentrations. The state-of-the-art has been briefly reviewed (for the United Kingdom) by the Air Quality Expert Group (9). In Appendix 2 of that report factors affecting diffusion tube performance are summarised and reviewed, and consequent recommendations for the use of diffusion tubes are made in section 4.3.2, in particular the need for specific, validated procedures to control the uncertainties in the measurement methods with the aim of providing long-term average $\mathrm{NO}_{2}$ concentration data with an uncertainty within $\pm 20 \%$.

\section{Theory}

The Palmes diffusion tube for passive sampling of nitrogen dioxide $\left(\mathrm{NO}_{2}\right)$ was originally developed as a personal monitor for the workplace (1). The principle of operation was described in some detail in the original paper, which noted the assumptions made in calculating the theoretical sampling rate. For a cylindrical tube diameter $d$ and length $l$, with a perfect sink (absorber) at one end, Fick's law of diffusion can be used to calculate a theoretical sampling rate (rate of net flow of a gas along the tube) as:

$$
F=-D \cdot \pi d^{2} / 4 l
$$

where $F$ is the sampling rate $\left(\mathrm{m}^{3} \mathrm{~s}^{-1}\right)$

$D$ is the molecular diffusion coefficient of $\mathrm{NO}_{2}$ in $\operatorname{air}\left(\mathrm{m}^{2} \mathrm{~s}^{-1}\right)$

For a given $\mathrm{NO}_{2}$ concentration of $\mathrm{C} \mathrm{g} \mathrm{m}^{-3}$, the mass of $\mathrm{NO}_{2}$ trapped at the (perfect) sink is then F.C g s${ }^{-1}$ (Figure 1).

The assumptions made in determining a theoretical sampling rate are:

- $\quad D$ is known for $\mathrm{NO}_{2}$ in air, along with its dependence on temperature, pressure, humidity (i.e. presence of water vapour)

- The absorber is perfect

- The absorbed gas can be measured quantitatively

- There is no absorption or adsorption by the tube walls 
- No chemical reactions occur in the tube during sampling that would affect the $\mathrm{NO}_{2}$ concentration

- The concentration is maintained constant at the entrance to the tube

If all these assumptions are valid, or are sufficiently good that the error introduced is small, then the geometry of the tube ( $l$ and $d$ ) gives an absolute sampling rate, i.e. the passive sampler does not require calibration.

Each of these assumptions has to be examined in order to evaluate the conditions under which the passive sampler will provide a reliable long-term average estimate of the air concentration of $\mathrm{NO}_{2}$.

FIGURE 1 NEAR HERE

\subsection{The Coefficient of Molecular Diffusion, $D$}

In the original paper (1), the diffusion coefficient for $\mathrm{NO}_{2}$ in air was given as:

$$
D=0.001858 \mathrm{~T}^{1.5}\left[\left(\mathrm{M}_{1}+\mathrm{M}_{2}\right) / \mathrm{M}_{1} \mathrm{M}_{2}\right]^{0.5} / \mathrm{P} \sigma^{2}{ }_{12} \Omega_{\mathrm{D}}
$$

where $\mathrm{M}_{1}$ and $\mathrm{M}_{2}$ are the molecular masses of gases 1 and 2,

$\sigma_{12}$ is the Lennard-Jones force constant for the mixture

$\Omega_{\mathrm{D}}$ is the collision integral

This gave a value for $D$ of $1.54 \times 10^{-5} \mathrm{~m}^{2} \mathrm{~s}^{-1}$ at $21.1^{\circ} \mathrm{C}\left(70^{\circ} \mathrm{F}\right)$ and $1 \mathrm{~atm}$ pressure.

More recently, the molecular diffusion coefficient of $\mathrm{NO}_{2}$ (and other gases) has been reviewed (10). The value for $\mathrm{NO}_{2}$ has never been directly measured, partly because of its dimerisation to $\mathrm{N}_{2} \mathrm{O}_{4}$ (important at higher concentrations than found in ambient air). The preferred value for $\mathrm{NO}_{2}$ in air, with an uncertainty of $\pm 10 \%$, is $1.36 \times 10^{-5}$ $\mathrm{m}^{2} \mathrm{~s}^{-1}$ at $0{ }^{\circ} \mathrm{C}$ and $1 \mathrm{~atm}$. Correcting to $21.1{ }^{\circ} \mathrm{C}$ using the temperature factor $\left(\mathrm{T} / \mathrm{T}_{0}\right)^{1.81}$ as recommended by Massman (1998), rather than using the exponent of 1.5 used by Palmes et al. (1976), gives a value for $D_{294}$ of $1.56 \times 10^{-5} \mathrm{~m}^{2} \mathrm{~s}^{-1}$ (cf. $1.54 \times 10^{-5} \mathrm{~m}^{2} \mathrm{~s}^{-1}$ ).

The effects of water vapour in the atmosphere on the diffusion of $\mathrm{NO}_{2}$ is negligible (7).

The temperature dependence of $D$ varies as $\left(\mathrm{T} / \mathrm{T}_{0}\right)^{1.81}$, implying a fairly large variation with temperature. However, the mass $(\mathrm{g})$ of $\mathrm{NO}_{2}$ collected by the sampler depends on the product of $D$ and the gas concentration in air $\left(\mathrm{g} \mathrm{m}^{-3}\right)$. For a given mixing ratio (partial pressure) of $\mathrm{NO}_{2}$ in air, the mass per unit volume changes as $\mathrm{T}^{-1}$, so if monitoring results are expressed as a mixing ratio (ppbV) then the temperature dependence varies as $\left(\mathrm{T} / \mathrm{T}_{0}\right)^{0.81}$, equivalent to a $3 \%$ change in $D$ per $10{ }^{\circ} \mathrm{C}$ change in temperature at $\mathrm{T}=15^{\circ} \mathrm{C}$.

For a typical 'Palmes' tube of length $71 \mathrm{~mm}$ and internal diameter $9.5 \mathrm{~mm}$, the sampling rate corresponds to $0.92 \mathrm{~cm}^{3} \min ^{-1}\left(55 \mathrm{~cm}^{3} \mathrm{~h}^{-1}\right)$ at $21^{\circ} \mathrm{C}$.

Attempts to calculate the sampling rate from first principles, while instructive in terms of the relative concentrations along the sampling tube, have not reproduced either the theoretical or measured sampling rates (11), but have been used to estimate that an 
$\mathrm{NO}_{2}$ molecule spends about $27 \mathrm{~s}$ in the tube prior to capture by the sorbent (12). This time is shorter than the residence time calculated from the diffusion coefficient $(D)$ of $2.8 \min (168 \mathrm{~s})(13)$.

\subsection{The absorber is perfect}

Consideration of triethanolamine as an absorbent is dealt with in detail in section $\$ \$$, but there is no evidence to suggest anything other than $100 \%$ efficiency except at very low temperatures or humidities.

\subsection{The absorbed gas can be measured quantitatively}

This assumption is discussed in detail in section 4, and relies on knowledge (or assumptions) about the chemical reactions occurring in the absorption process, and the possibility of chemical changes in the trapped material during sampling and/or storage prior to analysis. Interference from gases other than $\mathrm{NO}_{2}$ is discussed in section 4.2.

\subsection{There is no absorption or adsorption by the tube walls}

One early study in a chamber experiment (14) observed sampling rates that were lower than the theoretical rates, and increasing blank levels with increasing storage time of prepared tubes. The author ascribed these results to adsorption of $\mathrm{NO}_{2}$ on the acrylic walls; desorption from the walls of previously exposed tubes during storage was postulated to have caused the increase in blank levels. Soaking the tubes in $1 \mathrm{M}$ $\mathrm{NaOH}$ prior to use led to no increase in blank levels on storage, but loss of $70 \%$ of the expected $\mathrm{NO}_{2}$ on exposure in a laboratory chamber, presumably because of adsorption on the cleaned (and possibly activated) walls. Stainless steel tubes were suggested as alternatives, but these gave a consistent unexplained high bias. Solubility of $\mathrm{NO}_{2}$ in the plastic used to construct the sampling tubes was suggested as a source of contamination of blank tubes (15). Long-term (week or more) exposure in the field is likely to show little net effect of transient adsorption and desorption from walls provided that the walls themselves have not been 'activated' as above. However, desorption may be a source of noise for blank tubes, leading to uncertainty under conditions when very low ambient concentrations are being measured.

A different approach (16) used polythene tubes, which were cut into pieces after exposure, or disassembled, before extraction and analysis. Less than $5 \%$ of the total trapped $\mathrm{NO}_{2}$ was found on the tube walls (unlike $\mathrm{SO}_{2}$ or $\mathrm{NO}_{3}^{-}$, which showed significant adsorption on the walls), $80 \%$ was found on the triethanolamine-coated grids, and $15 \%$ in or on the cap. It is possible that some of the $\mathrm{NO}_{3}{ }^{-}$found on the tube walls could have come from oxidation in situ of adsorbed $\mathrm{NO}_{2}$, but was ascribed to capture of fine $\mathrm{NO}_{3}^{-}$particles and/or nitric acid.

\subsection{No chemical reactions occur in the tube that would affect the $\mathrm{NO}_{2}$ concentration during sampling}

The possibility of chemical reaction in the tube during sampling was first addressed as early as 1986 (17), but dismissed as likely to be small. The most likely interfering reaction is between $\mathrm{NO}$ and $\mathrm{O}_{3}$ to give $\mathrm{NO}_{2}$. In the atmosphere in daylight a balance is set up between the reaction of $\mathrm{NO}$ with $\mathrm{O}_{3}$ to produce $\mathrm{NO}_{2}$ and the photolysis of $\mathrm{NO}_{2}$ in UV light to give $\mathrm{NO}$ and $\mathrm{O}_{3}$. This 'photostationary equilibrium' is in fact rarely at equilibrium in the dynamic atmosphere of a city, or in cloudy weather where sunlight 
intensity changes on a timescale of minutes. Within an acrylic tube (the standard Palmes design) light levels are greatly attenuated (13) so that the 'equilibrium' is disturbed; $\mathrm{NO}_{2}$ is not photolysed, but $\mathrm{NO}$ continues to react with $\mathrm{O}_{3}$ within the tube. This becomes important because the time scale of residence of molecules in the sampling tube (minutes) is the same as for the reaction between $\mathrm{NO}$ and $\mathrm{O}_{3}$ at typical concentrations. If one considers only the lack of photolysis, then this effect is rather small $(17,18)$. However, in urban areas close to emissions of NO, air entering the tube is rarely at photochemical equilibrium because of the need for polluted air to be mixed with ozone-rich air before $\mathrm{NO}_{2}$ can be formed. Explicit consideration of the disequilibrium close to sources of NO leads to modelled estimates of 'over-reading' compared with continuous analyzers that are much greater (up to 40\%) (13). This non-equilibrium model has been shown to provide excellent agreement with comparisons of diffusion tubes and continuous analyzers in cities, close to NO sources (19), and is a major source of uncertainty in the use of passive diffusion tubes of the Palmes design close to roads. The greatest uncertainty was shown to occur when $\mathrm{NO}_{2}$ makes up $50 \%$ of the total $\mathrm{NO}_{\mathrm{x}}$ concentration.

In field studies, the use of tubes of different lengths has also indicated the role of within-tube chemistry. Effective sampling rates (corrected for tube length) should be the same for all tube lengths - within-tube chemistry would be expected to increase the effective sampling rate with length because of increased residence time in the tube, and this has been observed (20). The effect of wind speed on different lengths of tube would be to decrease the relative sampling rate as tube length increased (see below, section 3.1). Further experiments, using quartz and acrylic tubes of different lengths (21) demonstrated the importance of within-tube chemistry to the effective sampling rate; quartz tubes, which transmit UV light and permit $\mathrm{NO}_{2}$ photolysis during sampling, gave significantly smaller concentrations than acrylic tubes of the same length, and were in much better agreement with co-located automatic samplers.

Badge-type samplers, with much shorter diffusion path lengths, do not suffer from this artefact because the residence time of molecules within the tube is much shorter, but they are subject to other sampling problems, as discussed below (Section 2.6).

\subsection{The concentration is maintained constant at the entrance to the tube}

This assumption covers two types of variation: systematic depletion of $\mathrm{NO}_{2}$ concentrations caused by uptake within the tube, and the departure from steady-state conditions (under which the theory was developed) in the real atmosphere. Depletion caused by uptake within the tube is not important for the Palmes design of sampler; the depth of the depleted boundary layer at the entrance to the tube has been calculated as $<1.5 \mathrm{~mm}$ at wind speeds of $>0.6 \mathrm{~m} \mathrm{~s}^{-1}$ (22). Badge type samplers with much faster sampling rates (shorter diffusion distances) have much greater uncertainties, because the depleted zone at the entrance to the tube is deeper and more dependent on wind speed, and this depth is a much greater proportion of the diffusion length within the sampler.

The assumptions made in deriving the theoretical sampling rate (of constant concentration at the entry to the tube) have been shown to be valid (23) provided that the characteristic fluctuation time is $40 \%$ longer than the residence time in the tube (2.8 min for $\mathrm{NO}_{2}(13)$ ). This may not hold for kerb-side sampling. In the simplest 
case, where there is no chemical reaction in the tube, application of a sinusoidal variation in external concentrations changed the theoretical sampling rate by less than $1 \%$ unless peak concentrations lasted less than 25 minutes, when a $5 \%$ greater sampling rate was predicted. A typical worst-case scenario was predicted to have a bias of around $+2 \%$ over 2 weeks (24).

The uncertainty in the effective tube length caused by wind-induced turbulence has been explored in some detail; the results are described below (section 3.1).

\subsection{Conclusions}

Most of the original assumptions are met in practice to within a few percent, except under certain well-defined conditions. The major exception is the assumption of no chemical reaction within the tube during sampling, which in turn is influenced by the assumption of constant concentrations at the entrance to the tube. This assumption can lead to systematic positive bias (over-read) of up to $40 \%$ in conditions where $\mathrm{NO}$ and $\mathrm{O}_{3}$ concentrations are not in equilibrium, i.e. close to dynamic sources of $\mathrm{NO}$, such as at kerb sides or in street canyons.

\section{The role of meteorological conditions during sampling}

\subsection{Windspeed}

The original design (1) was tested for the effects of wind speed in the laboratory using tubes set at 5 angles and 5 distances along a rotating rod, to give exposures in the range $103-515 \mathrm{ft} / \mathrm{min}(0.52$ to $2.62 \mathrm{~m} / \mathrm{s})$. The experiments were done using water vapour rather than $\mathrm{NO}_{2}$. As expected, higher wind speeds led to higher sampling rates, with the smallest increase in tubes at $180^{\circ}$ to the wind direction (away from the wind); those mounted at right angles gave sampling rates that were higher than in still air by $6-20 \%$. Over all angles, the average sampling rate increased by $3 \%$ for an increase in wind speed of $0.05 \mathrm{~m} \mathrm{~s}^{-1}(25)$. More recent chamber studies showed a dependence on wind speed represented by:

$$
\begin{gathered}
\text { sampling rate }\left(\mathrm{cm}^{3} \mathrm{~h}^{-1}\right)=-11 \mathrm{Ws}^{2}+54 \mathrm{Ws}+63.6, \\
\text { where } \mathrm{Ws} \text { is in the range } 0.1 \text { to } 2.5 \mathrm{~m} \mathrm{~s}^{-1},
\end{gathered}
$$

compared with a theoretical sampling rate of $72.8 \mathrm{~cm}^{3} \mathrm{~h}^{-1}$ for the conditions used (26). This is equivalent to an increase in sampling rate of $104 \%$ between 0 and $2.5 \mathrm{~m} \mathrm{~s}^{-1}$. The effect of wind speed on sampling rate has also been quantified in a laboratory factorial experiment looking at the effects of wind speed $\left(0.8\right.$ or $\left.3.6 \mathrm{~m} \mathrm{~s}^{-1}\right)$, temperature and humidity on sampling rate (27). The best fit to the data was given by:

$$
\text { sampling rate }\left(\mathrm{ng} \mathrm{ppb} \mathrm{pin}^{-1}\right)=7.40 \times 10^{-4}+5.81 \times 10^{-4} \mathrm{Ws}\left(\mathrm{m} \mathrm{s}^{-1}\right)+2.72 \times 10^{-5} \mathrm{~T}
$$

$$
\left({ }^{\circ} \mathrm{C}\right)+1.43 \times 10^{-5} \mathrm{RH}(\%) \text {. }
$$

For conditions of $20{ }^{\circ} \mathrm{C}$ and $75 \% \mathrm{RH}$, this is equivalent to an increase in sampling rate from 0.0024 to $0.0038 \mathrm{ng} \mathrm{ppb}^{-1} \mathrm{~min}^{-1}$ (or $60 \%$ ) between 0 and $2.5 \mathrm{~m} \mathrm{~s}^{-1}$. 
Exposure of tubes of different lengths $(35,50$ and $71 \mathrm{~mm})$ to $\mathrm{NO}_{2}$ over 4 days in a wind tunnel at different angles to the air flow, at wind speeds up to $12 \mathrm{~m} \mathrm{~s}^{-1}$, showed that the effective reduction in tube length was around $10 \mathrm{~mm}$ at $1.5 \mathrm{~m} \mathrm{~s}^{-1}$ rising to 30 $\mathrm{mm}$ at $12 \mathrm{~m} \mathrm{~s}^{-1}$ (28). These results showed that the effective shortening of the tube was the same, irrespective of tube length, and therefore attributable to turbulence around the tube entrance. The effect was greater for tubes mounted at $75^{\circ}$ to the flow than perpendicular to the flow. More recently, laboratory experiments have shown measured concentrations increasing slightly with increasing wind speed (29). The use of a protective shelter to house replicate diffusion tubes greatly reduced the effects of wind speed (30) in a laboratory experiment at wind speeds up to $4.5 \mathrm{~m} \mathrm{~s}^{-1}$, emphasising the need to know the actual velocity of the wind (and turbulence conditions) at the entrance to the tube, rather than a measured wind speed at some point near the exposure site.

In the field, the comparison between results obtained using diffusion tubes and using automatic monitors has been evaluated in terms of wind speed measured at the site. However, measurements of wind speed are rarely, if ever, made at the face of the sample tubes, but at some point (usually unspecified) nearby. Therefore, the relationship (if any) between mean wind speed at a site and effective sampling rate is difficult to discern. Some authors have recognised this problem, and have estimated the wind speed at the height of the samplers from measurements at $10 \mathrm{~m}(27)$ in an effort to relate the sampling results to actual wind speeds at the point of sampling.

The use of different tube lengths outdoors (28) showed no effects of mean wind speed in the range 2.3 to $4.5 \mathrm{~m} \mathrm{~s}^{-1}$; tubes of different length $(35,50,71 \mathrm{~mm})$ gave identical concentrations, implying that the effective sampling lengths were as measured, with no shortening caused by differences in wind speed. A similar experiment was conducted several years later using tubes of 6 different lengths mounted on a roof (31). The results were noisy (despite a precision for triplicate tubes of 3\%) suggesting complex turbulence conditions at that particular (rooftop) site. There was a small but not statistically significant effect of increasing wind speed in the range 2 to $6.5 \mathrm{~m} \mathrm{~s}^{-1}$ on sampling rates; all tubes sampled with an effective diffusion length that was on average $18 \mathrm{~mm}$ less than the measured tube length. The use of grids with a $2 \mathrm{~mm}$ mesh across the tube entrance removed the effects of wind-induced turbulence on the diffusion length, but reduced the overall sampling rate below the theoretical value, so that the sampling rate would have had to be calibrated for quantitative use. In their modelling of the situation, the authors took no account of chemical reactions inside the tube during sampling, which may have affected the apparent sampling rates outdoors. More recent experiments outdoors with tubes of different lengths and of different materials (acrylic vs. quartz) (21) showed no effect of diffusion length for quartz samplers at 120 or $71 \mathrm{~mm}$, implying no effect of wind shortening, although enhanced sampling attributed to wind shortening was observed for the shortest diffusion length $(40 \mathrm{~mm})$. The difference between the different tube materials was dependent on tube length. The authors concluded that the main effect of tube length was on chemical processes occurring inside the tube (see above, Section 2.5) rather than on effective sampling rate influenced by wind speed, with the exception of the shortest tube, where interference from the sample holder or length:diameter ratio were suggested as reasons for the apparent breakdown of a simple diffusion process. 
Several studies have considered the possible effects of mean wind speed during a sampling period on the comparison between diffusion tube results and an automatic monitor. (17) saw no effect of wind speed in the range 1.0 to $4.5 \mathrm{~m} \mathrm{~s}^{-1}$ for 1 week exposure of Palmes tubes. A similar lack of correlation with wind speed has been reported by other authors for outdoor samplers $(21,30)$, although unsheltered diffusion tubes have shown larger (up to 18\%) apparent sampling rates than adjacent sheltered tubes $(32,33)$, which may be an effect of wind speed or turbulence. Similar lower sampling rates in sheltered tubes compared with adjacent unsheltered tubes have been noted in other studies (27). The use of some type of shelter, from rain, direct sunlight and/or wind turbulence, is fairly commonplace $(30,34)$ although the relative effects of sheltering from direct sunlight and wind have not been explicitly considered. Some authors advise against using a shelter on the grounds that it alters the chemical composition of the sampled air through shading (21).

Effects of wind speed are much more important for badge type samplers with very short diffusion paths. Although this type of sampler gives much faster sampling rates, the use of membranes or grids at the face of the sampler, to minimise effects of windinduced shortening, means that diffusion (i.e. sampling) rates cannot be deduced from first principles, and each design must be calibrated. Alternatively, samplers of two different lengths must be exposed simultaneously (35). Sampling rates for some designs are dependent on temperature, relative humidity and wind speed (36). The much faster sampling rate also means increased depletion in the air around the face of the sampler if not replenished by external air movement; required wind speeds to prevent depletion are typically at least $0.6 \mathrm{~m} \mathrm{~s}^{-1}(35,37)$.

\section{Conclusion}

Effects of wind speed or turbulence that are demonstrated in exposure chambers or wind tunnels in the laboratory are not observed under field conditions. This is probably because the turbulence conditions in the laboratory are measured at the mouth of the tube, whereas in the field wind speeds are measured at some distance (horizontally and/or vertically) from the tube opening. Both wind speed and degree of turbulence at the tube entrance may be very different from the reported field measurements, and may be very much smaller than those recorded, especially if tubes are mounted in a shelter. Actual face velocities in the field have not been measured, and are probably not predictable, given the complexity of the air flow around most installations. Several authors note reduced sampling rates when tubes are placed in a shelter compared to non-sheltered tubes exposed nearby - provided this does not lead to local depletion through air stagnation it would appear that routine use of a shelter is likely to lead to a lower risk of positive bias caused by turbulence.

\subsection{Temperature}

The theoretical effects of temperature on sampler performance can be separated into effects on the diffusion coefficient $(D)$, and on the units of gas phase concentration ( $\mathrm{g}$ $\mathrm{m}^{-3}$, which is $\mathrm{T}$ dependent, or ppbV, which is not). As shown above (Section 2.1), this leads to a dependence of the sampling rate on $\mathrm{T}^{1.81}$ or $\mathrm{T}^{0.81}$ for concentrations measured in $\mathrm{g} \mathrm{m}^{-3}$ or $\mathrm{ppbV}$, respectively (10).

However, experimental measurements of sampling rate as a function of temperature have sometimes shown a much greater $\mathrm{T}$ dependence. One of the earliest tests of the Palmes design showed a $15 \%$ decrease in sampling rate between $27{ }^{\circ} \mathrm{C}$ and $15{ }^{\circ} \mathrm{C}$, 
compared with a theoretical change of $<2 \%$. This was ascribed to a phase change from solid to liquid in the absorbent (triethanolamine) at $21{ }^{\circ} \mathrm{C}(38)$. However, the role of the melting point of TEA was challenged by a later study (39), which showed that TEA solutions did not freeze, but formed a gel even at temperatures as low as -10 ${ }^{\circ} \mathrm{C}$. The role of triethanolamine (TEA) as an absorbent is discussed below (Section 4.1). The effectiveness of TEA as an absorbent appears to be dependent on humidity, and some of the reported effects of temperature on sampling rate may be confounded by simultaneous changes in absolute humidity (40) leading to low effective sampling rates at low temperatures that are caused by a lack of water vapour rather than low temperatures per se $(29,41,42)$. One laboratory study (designed to evaluate Palmes tubes for use in Greenland) showed almost constant sampling rates from $20^{\circ} \mathrm{C}$ down to $-8{ }^{\circ} \mathrm{C}$, then a linear decrease to around $30 \%$ of the constant rate, at $-28{ }^{\circ} \mathrm{C}(43)$. Another laboratory study found no temperature dependence between 5 and $45{ }^{\circ} \mathrm{C}$ (30), while another study found an effect of extremes of $\mathrm{T}$ and relative humidity on sampling rates, and low sampling rates in the field in winter (by comparison with an automatic monitor) (44).

For short-path 'badge' type samplers the effectiveness of the absorbent may be limited by the rate of diffusion in the liquid phase (45), but this is unlikely to be an issue for the Palmes type, which has much slower sampling rates. Comparisons of a short path sampler with an active sampler suggest a dependence on $\mathrm{T}$ of around 1\% per ${ }^{\circ} \mathrm{C}$ (46). Different designs of sampler have different temperature responses, which must be characterised before they can be used (36).

High temperatures during storage after sampling may also lead to losses or reductions in the apparent sampling rate for $\mathrm{NO}_{2}(47)$ - see Section 5.2.

\section{Conclusion}

The dependence of sampling rate on temperature is small and predictable, except in cold dry air. This deviation from theory is related to the use of triethanolamine as the absorbent and appears to be caused by a lack of sufficient water vapour to ensure quantitative conversion of trapped $\mathrm{NO}_{2}$ to $\mathrm{NO}_{2}^{-}$ions.

\subsection{Humidity}

The effects of humidity on sampling rates appear to be related to the use of triethanolamine (TEA) as an absorbent for $\mathrm{NO}_{2}$, rather than any effect on the diffusion process. Most laboratory studies have used relative humidity $(\mathrm{RH})$ as a measure of water vapour concentration, rather than absolute humidity, which may be more important. Early studies showed no effect of RH on a short path sampler between 20 and $60 \%$ at room temperature (48). This was confirmed by subsequent studies with $\mathrm{RH}>20 \%$ at ambient temperatures $(30,49)$. Studies with Palmes tubes between 5 and $85 \% \mathrm{RH}$ at room temperatures (above $22{ }^{\circ} \mathrm{C}$ ) showed a weak linear dependence of the sampling rate (expressed as changes in the diffusion coefficient) given by (50):

$$
D\left(\mathrm{~m}^{2} \mathrm{~s}^{-1}\right)=1.20 \times 10^{-5}+3.8 \times 10^{-8} \mathrm{RH}(\%)
$$

This is equivalent to an $18 \%$ change in uptake rate between 20 and $80 \% \mathrm{RH}$.

More recent studies have demonstrated a dependence on absolute humidity, expressed in terms of the uptake rate for a membrane-capped tube (51): 


$$
\text { Uptake }\left(\mathrm{cm}^{3} \mathrm{~h}^{-1}\right)=42.9+8.9 \ln \left[\mathrm{H}_{2} \mathrm{O}\right] \text {, where }\left[\mathrm{H}_{2} \mathrm{O}\right] \text { is in } \mathrm{g} \mathrm{m}^{-3} \text {. }
$$

This is equivalent to a $23 \%$ change in uptake rate between 20 and $80 \% \mathrm{RH}$ at $20{ }^{\circ} \mathrm{C}$. A small decrease in uptake rate with time over the first week of this experiment was ascribed to loss of $\mathrm{H}_{2} \mathrm{O}$ from the absorbent.

Drying induced by lowering the total pressure during sampling also caused reduced sampling efficiency (52). Effects on sampling rate caused by changing pressure (to simulate increasing altitude) would not be expected, based on the theory of diffusional sampling, but observed changes may be attributed to loss of water vapour from the absorbent (TEA), leading to reduced sampling efficiency. This would be consistent with a greater effect of lowering pressure shown using shorter tubes (53), from which water would evaporate more quickly.

The effects of variations in absolute humidity on a short path sampler have also been reported, with significant reductions in uptake at low RH at low temperatures $(40,42)$. More generally, a dependence on RH is an important factor in some passive sampler designs (36).

Effects of humidity on sampler performance in the field have also been noted (30), with uptake rates given by (27):

$$
\mathrm{U}(\mathrm{ng} / \mathrm{ppb} / \mathrm{min})=7.40 \times 10^{-4}+2.72 \times 10^{-5} \mathrm{~T}\left({ }^{\circ} \mathrm{C}\right)+1.43 \times 10^{-5} \mathrm{RH}(\%)+5.81 \times 10^{-4} \mathrm{~W}(\mathrm{~m} / \mathrm{s})
$$

This is equivalent to a change of $17 \%$ in uptake rate between 20 and $80 \% \mathrm{RH}$ at $20{ }^{\circ} \mathrm{C}$ and $1 \mathrm{~m} \mathrm{~s}^{-1}$. If the uptake rate is dependent on absolute humidity, the above equation may not present a true picture of the dependence on $\mathrm{T}$ and $\mathrm{RH}$, because $\mathrm{RH}$ is a function of water vapour concentration (absolute humidity) and temperature. However, the two equations (one based on $\left[\mathrm{H}_{2} \mathrm{O}\right]$ and the other on $\mathrm{T}$ and $\mathrm{RH}$ ) provide very similar patterns of variation (Figure 2 ).

\section{FIGURE 2 NEAR HERE}

A similar equation was reported by Plaisance et al. (2004) from a chamber study in terms of the deviation in sampling rate from standard conditions $\left(20{ }^{\circ} \mathrm{C}\right.$ and $50 \% \mathrm{RH}$, wind speed $0.54 \mathrm{~m} \mathrm{~s}^{-1}$ ):

$$
\mathrm{V}_{\mathrm{SR}}\left(\mathrm{m}^{3} \mathrm{~s}^{-1}\right)=0.9+2.85 \times 10^{-3} \mathrm{~T}\left({ }^{\circ} \mathrm{C}\right)-1.62 \times 10^{-4} \mathrm{RH}(\%)+4.96 \times 10^{-5} \mathrm{~T} . \mathrm{RH}
$$

In comparing results from passive diffusion tubes with those from automatic analyzers, however, it is important to note that automatic $\mathrm{NO}_{2}$ analyzers also have a dependence on humidity, which may not have been allowed for in comparing the response of diffusion tubes relative to automatic methods. A chemiluminescent NOx analyzer response typically decreases by $0.5 \%$ per $\mathrm{g} \mathrm{H}_{2} \mathrm{O} \mathrm{m}{ }^{-3}$ absolute humidity (26). This is equivalent to a change of $5 \%$ between 20 and $80 \% \mathrm{RH}$ at $20{ }^{\circ} \mathrm{C}$.

\section{Conclusion}

Humidity is probably the most important environmental variable that affects the performance of passive diffusion samplers using TEA as absorbent. TEA does not perform quantitatively at low humidities (see Section 4.1). The data of Hansen et al. 
(2001) suggest a loss of efficiency below $-8{ }^{\circ} \mathrm{C}$, equivalent to an air concentration of water vapour of $2.9 \mathrm{~g} \mathrm{~m}^{-3}(0.35 \mathrm{kPa})$, or $35 \% \mathrm{RH}$ at $5{ }^{\circ} \mathrm{C}$. At any given temperature the effect of a change in relative humidity between $20 \%$ and $80 \%$ is to change sampling rates by about $\pm 15 \%$ relative to the values at $50 \% \mathrm{RH}$. In practice, the dependence on humidity has rarely been tested in the field, and the interaction between humidity and the reaction of TEA with $\mathrm{NO}_{2}$ has not been investigated systematically.

\section{The role of the absorbent medium and subsequent analysis of trapped $\mathrm{NO}_{2}$}

\subsection{Triethanolamine}

Triethanolamine $\left(2,2^{\prime}, 2^{\prime \prime}\right.$-nitrilotriethanol $\left(\mathrm{C}_{2} \mathrm{H}_{4} \mathrm{O}\right)_{3} \mathrm{~N}$, referred to as TEA) is a hygroscopic pale yellow liquid with a melting point of $21.6^{\circ} \mathrm{C}$. It has been used as an absorbent for sampling $\mathrm{NO}_{2}$ since the 1970s, initially in solution in a bubbler or impinger, or in the solid phase on molecular sieve (54). Its capacity to remove $\mathrm{NO}_{2}$ from the sampled air is high (90-100\%), based on sequential sampling. However, not all of the absorbed $\mathrm{NO}_{2}$ is necessarily available for chemical analysis as nitrite $\left(\mathrm{NO}_{2}{ }^{-}\right)$ ion. Several stages in the trapping and analysis process must be identified in order to understand the overall sampling efficiency:

(1) capacity to remove $\mathrm{NO}_{2}$ from a sample air stream, as determined by sequential sampling. This is usually $100 \%$ efficient unless high $\mathrm{NO}_{2}$ concentrations or sampling rates exceed the capacity of the absorbent to react;

(2) reaction with TEA to form a product that liberates $\mathrm{NO}_{2}^{-}$ions on addition of water. This reflects the stoichiometry of the reaction to form an adduct, and the subsequent reaction of the adduct with water;

(3) losses of trapped $\mathrm{NO}_{2}$ during and after sampling and before analysis. These may be through thermal decomposition or photolysis (see below, Section $\$ \$$ ) but are not likely to be caused by release of $\mathrm{NO}_{2}$ from the absorbent - application of pressures as low as 0.2 atm led to no losses of trapped $\mathrm{NO}_{2}$ from TEA (53).

There is some uncertainty as to the overall stoichiometry of the process, with early authors suggesting as low as $67 \%$ conversion to $\mathrm{NO}_{2}^{-}$, but showing increasing conversion as concentrations decreased, towards $100 \%$ conversion at concentrations typical of ambient air (54-56). These studies used the colorimetric diazotisation reaction with sulphanilamide and $\mathrm{N}$-(1-naphthyl)-ethylenediamine (NEDA) to detect the $\mathrm{NO}_{2}^{-}$formed.

The nature of the reaction product, and the conditions under which it forms, appear to be critical. Reacting gram quantities of $\mathrm{NO}_{2}$ and TEA in aqueous solution gave equimolar amounts of $\mathrm{NO}_{2}^{-}$and TEA-nitrate (i.e. $50 \%$ conversion of $\mathrm{NO}_{2}$ to $\mathrm{NO}_{2}^{-}$) (57). Similar results were obtained by conducting the reaction in dichloromethane as a solvent, with water present in equimolar concentrations. However, reaction of $\mathrm{NO}_{2}$ with TEA in dry solvent at $-5{ }^{\circ} \mathrm{C}$ gave the nitroso ammonium salt. It was suggested that the reaction proceeded via $\mathrm{N}_{2} \mathrm{O}_{4}$, and that concentrations of $\mathrm{NO}_{2}>10 \mathrm{ppmV}$ would give $50 \%$ conversion. 
Subsequent studies showed that the humidity was important in determining the reaction pathway, with a higher fraction of $\mathrm{NO}_{2}$ converted to $\mathrm{NO}_{2}^{-}$at higher relative humidities (58). The decrease in $\mathrm{NO}_{2}^{-}$production at low $\mathrm{RH}$ was ascribed to formation of different products (52). Experiments with TEA supported on silica in a 'Sep-pak' used for both active and passive sampling and analysed by ion chromatography (IC) showed $90 \%$ formation of $\mathrm{NO}_{2}^{-}$and $10 \%$ formation of $\mathrm{NO}_{3}^{-}$, although overall trapping efficiency in this system was only around $90 \%$ (59). In a different study using a similar technique the fractions of $\mathrm{NO}_{2}^{-}$and $\mathrm{NO}_{3}^{-}$recovered were $77 \%$ and $23 \%$ respectively (60). The use of IC for analysis, while providing information on both $\mathrm{NO}_{2}^{-}$and $\mathrm{NO}_{3}^{-}$, is also subject to problems when using TEA, because of the effects of TEA on eluent $\mathrm{pH}$ which can lead to systematic errors in quantifying $\mathrm{NO}_{2}^{-}$and $\mathrm{NO}_{3}{ }^{-}$concentrations (61). In this study, the overall conversion of $\mathrm{NO}_{2}$ to $\mathrm{NO}_{2}^{-}$was $74 \%$.

The reaction mechanism of $\mathrm{NO}_{2}$ with TEA has been studied for high $\mathrm{NO}_{2}$ concentrations $(10 \mathrm{ppm})$ in dry air, and the products formed were identified (after a process of acetylation) as N-nitrosodiethanolamine (Figure 1) (62). However, triethanolamine nitrate and triethanolamine nitrite were identified as the major reaction products in a subsequent study, with $\mathrm{N}_{2} \mathrm{O}_{4}$ suggested as the reactive intermediate, yielding an overall stoichiometry of 0.5 for $\mathrm{NO}_{2}->\mathrm{NO}_{2}^{-}(63)$. The role of water in the reaction to produce a stoichiometry of 1 was shown by the production of triethanolamine $\mathrm{N}$-oxide as the major product of reaction of $\mathrm{NO}_{2}$ with TEA in atmospheric sampling. TEA N-oxide reacts quantitatively to give $\mathrm{NO}_{2}^{-}$ions (64). However, the presence of liquid water in the trapping medium (TEA solution, $2 \mathrm{~g} \mathrm{l}^{-1}$ ) appears to result in equimolar production of $\mathrm{NO}_{2}^{-}$and $\mathrm{NO}_{3}^{-}(65)$.

\section{Conclusion}

The availability of water is crucial to the way in which TEA reacts with $\mathrm{NO}_{2}$. Too much water (aqueous solution) yields $\mathrm{NO}_{2}^{-}$and $\mathrm{NO}_{3}{ }^{-}$in equal amounts. Absence of water yields N-nitroso DEA and no $\mathrm{NO}_{2}^{-}$. A mole ratio of $\mathrm{H}_{2} \mathrm{O}$ :TEA of around 3.6, which is the amount absorbed by TEA in equilibrium with ambient air at $75 \% \mathrm{RH}$ and $\left.26{ }^{\circ} \mathrm{C}\left(18 \mathrm{~g} \mathrm{H}_{2} \mathrm{O} \mathrm{m}^{-3}\right)(52)\right)$ provides $100 \%$ conversion of absorbed and reacted $\mathrm{NO}_{2}$ to $\mathrm{NO}_{2}^{-}$. As noted above (Section 3 ) the sudden decrease in sampling efficiency below -8 ${ }^{\circ} \mathrm{C}$ (43) suggests that a minimum of around $3 \mathrm{~g} \mathrm{H}_{2} \mathrm{O} \mathrm{m}^{-3}$ is required for TEA to be effective as the absorbent in passive diffusion samplers. This is unlikely to be a problem in UK conditions except in very cold, dry weather.

\subsection{Interferences}

In addition to its reaction with $\mathrm{NO}_{2}$, TEA also traps and reacts with other molecules to produce $\mathrm{NO}_{2}^{-}$ions on extraction into aqueous solution. The two most important potential positive interferences, apart from the reaction of $\mathrm{NO}$ with $\mathrm{O}_{3}$ during sampling (Section 2.5), are from peroxyacetyl nitrate (PAN) and nitrous acid (HONO). Dosing of TEA absorbent with $\mathrm{NO}_{3}^{-}$ions produces no interference (66). There is a negligible effect of exposure to $\mathrm{O}_{3}$ alone in the short term; $200 \mathrm{ppbV}$ for 12 h converted $<10 \%$ of trapped (reacted) $\mathrm{NO}_{2}$ to $\mathrm{NO}_{3}^{-}$(35); active co-sampling of 130 $\mathrm{ppbV} \mathrm{O}_{3}$ and $10 \mathrm{ppbV} \mathrm{NO}_{2}$ using TEA on a filter at $50 \% \mathrm{RH}$ produced no interference (41). 
Interference from PAN is important in that PAN is quantitatively converted to $\mathrm{NO}_{2}{ }^{-}$ on (naturally alkaline) TEA (60). The reaction of PAN appears to depend on the nature of the substrate on which the TEA is deposited for sampling; TEA on silica removes PAN from air but only gives $67 \%$ positive interference (61). TEAimpregnated filters collected PAN, but only $15-25 \%$ of the reacted PAN was present as $\mathrm{NO}_{2}^{-}$, the remainder being $\mathrm{NO}_{3}^{-}$(41). For Palmes type samplers, interference from PAN was $<5 \%$ (ppbV:ppbV) (67). In practice, interference from PAN is likely to be very small under UK conditions (68), although it could be a significant interference in California (69).

HONO gives $100 \%$ interference, producing $\mathrm{NO}_{2}^{-}$on reaction with TEA (41). However, HONO concentrations in UK air are small; even in cities they account for only a few $\%$ of $\mathrm{NO}_{2}$ concentrations (70). Moreover, both PAN and $\mathrm{HONO}$ would be measured quantitatively as positive interference by a chemiluminescent $\mathrm{NO}_{\mathrm{x}}$ analyzer using thermal conversion of $\mathrm{NO}_{2}$ (and PAN and HONO) to NO, so would not be identified as a positive interference when passive diffusion tube samplers are compared with continuous automatic samplers.

There are no reports of negative interference on sampling using Palmes tubes with TEA as absorbent, other than the effects of humidity and temperature noted above. However, several authors have reported losses during sampling, especially when comparing integrated sampling over 4 weeks with the sum of $4 \times 1$-weekly sampling. These losses appear to be related to degradation of the trapped $\mathrm{NO}_{2}$ by UV light (71). Non-blackened short-path polythene tubes lost up to $50 \%$ of absorbed $\mathrm{NO}_{2}$ over a month (72). With Palmes type tubes, losses of $\mathrm{NO}_{2}$ over several months, suggesting that the TEA- $\mathrm{NO}_{2}$ reaction product is degraded, led to the use of an alternative trapping medium (iodide + hydroxide or iodide + arsenite) $(73,74)$. Lower effective sampling rates over 4 weeks compared to $4 \mathrm{x} 1$ week, attributed to losses of sampled $\mathrm{NO}_{2}$, have been observed using quartz tubes (which transmit UV light) rather than acrylic tubes (which do not) (75).

\section{Conclusion}

Positive interference from other pollutant gases is likely to be negligible in UK conditions. However, the effects of sampling duration are important because of losses that occur during sampling, probably caused by photochemical reactions of the trapped $\mathrm{NO}_{2}$ (TEA-N-oxide) during sampling. These losses become significant over 4 weeks in comparison with 1-week sampling periods.

\subsection{Ion Chromatography}

The original method used by Palmes (1) for measurement of the trapped $\mathrm{NO}_{2}$ relied on the colorimetric determination of $\mathrm{NO}_{2}^{-}$using the diazotisation reaction with acidified sulphanilamide and N-(1-naphthyl)-ethylene diamine (NEDA), with detection and quantification of the pink colour produced using photometric absorption spectroscopy at $540 \mathrm{~nm}$. This colour reagent had long been used for the quantification of $\mathrm{NO}_{2}^{-}$in solution as 'Saltzman reagent'. The colorimetric method responds only to $\mathrm{NO}_{2}$, , and not to $\mathrm{NO}_{3}{ }^{-}$. Consequently, any $\mathrm{NO}_{3}{ }^{-}$produced during the reaction of $\mathrm{NO}_{2}$ with TEA would not be registered, leading to the possibility of underestimating $\mathrm{NO}_{2}$ uptake rates by TEA. 
However, several authors have used Ion Chromatography (IC) rather than colorimetry to quantify $\mathrm{NO}_{2}$ uptake. In an early study, uptake of $\mathrm{NO}_{2}$ by TEA coated onto molecular sieve was shown to lead to production of both $\mathrm{NO}_{2}^{-}$and $\mathrm{NO}_{3}^{-}$ions, especially at low relative humidities (58). Similar results were shown for TEA coated onto silica in 'Sep-pak' cartridges, with $90 \% \mathrm{NO}_{2}^{-}$and $10 \% \mathrm{NO}_{3}^{-}$formed from $\mathrm{NO}_{2}$ (59).

The benefit of using IC was recognised over 20 years ago, in terms of a greatly improved limit of detection using Palmes tubes, compared with colorimetric analysis (76). Using gradient elution IC, the limit of detection for Palmes type tubes was measured as 4 ppbV.h, compared with 33 ppbV.h for a colorimetric method (67). Other authors have shown a 14-fold decrease in the limit of detection (26). Potential problems with TEA affecting eluent $\mathrm{pH}$ (and thereby quantification of $\mathrm{NO}_{2}{ }^{-}$and $\mathrm{NO}_{3}{ }^{-}$ ions) in an isocratic system have been noted (61). Many authors only report the $\mathrm{NO}_{2}^{-}$ concentrations obtained using IC $(47,77)$, so it is not possible to establish whether $\mathrm{NO}_{3}{ }^{-}$is formed on exposure to $\mathrm{NO}_{2}$. However, one study did note that only $\mathrm{NO}_{2}{ }^{-}$ concentrations were needed to calculate atmospheric $\mathrm{NO}_{2}$ concentrations (15).

The technique has also been used for short-path samplers with faster sampling rates $(35,40,41,78)$

\section{Conclusion}

The colorimetric method for measuring $\mathrm{NO}_{2}^{-}$ions extracted from the samplers is quick, easy, low-cost, and the method of choice for most UK applications. Ion chromatography might provide additional useful information on the efficiency of the reaction between TEA and $\mathrm{NO}_{2}$ (from measurements of $\mathrm{NO}_{3}{ }^{-}$ions) and provides much lower detection limits if sampling low concentrations.

\section{Diffusion tube construction and use}

\subsection{Tube preparation}

The preparation of passive sampling tubes of the Palmes design has not been standardised, and different techniques lead to different results. Sampler tube preparation has been identified as the largest source of uncertainty when comparing the use of passive diffusion tubes for $\mathrm{NO}_{2}$ monitoring by different laboratories (71, 79-88).

Several different techniques have been used for loading TEA onto the grids. In the original design (1), 3 grids were used in each tube, coated in TEA by dipping them into a $50 \%$ solution of TEA in acetone. Grids were then dried (acetone allowed to evaporate) on absorbent paper. This gave an average of $0.95 \mathrm{mg}$ TEA per grid. This technique was modified to use a 1:7 v/v solution of TEA in acetone to avoid blocking the mesh with solid TEA (25). The use of a TEA solution in water, pipetted onto the grids, was introduced a decade later (28), and has been used as a standard method in the UK $(39,67)$. Methanol has also been used as a solvent to pipette aliquots of TEA solution onto grids pre-inserted into tube caps, because of problems with acetone reacting with the acrylic tubes; methanol evaporates more quickly than water (89). 
A 33\% solution of TEA in acetone was used with a single grid (90) but the authors noted a significant under-reading compared to automatic monitors. It is likely that this was caused by inefficient trapping or saturation of the TEA, because use of a single grid (using 20\% TEA in acetone) was shown to give only 50\% capture compared with an automatic analyzer, but the use of 2 grids solved this problem (16). Reports from the UK monitoring network also identified insufficient TEA on the grid as a problem $(81)$.

Different methods of preparation across the UK network were examined in a comparison in 1999 (82). The use of a 50\% solution of TEA in water, rather than in acetone, in preparing the grids gave a significantly smaller response (a bias relative to automatic analyzers of $-23 \% \mathrm{cf}$. $+11 \%$ for TEA/acetone), and a much larger variability (2.5 times larger s.d.). A more detailed study (39) used a variety of different preparation techniques, with 2 grids:

1. 50\% TEA in acetone, grids dipped (as for original Palmes method)

2. $10 \%$ TEA in water + a surfactant (Brij 35) pipetted onto grids in tube $(30 \mu \mathrm{l})$

3 . as (2) but with $20 \%$ TEA in water $(25,30$ and $50 \mu$ aliquots)

4. as (2) but with $50 \%$ TEA in water (30 and $50 \mu$ aliquots)

The amounts of TEA on both grids were ca. $7 \mathrm{mg}$ for (1), $3 \mathrm{mg}$ for (2), $5 \mathrm{mg}$ for $50 \mu \mathrm{l}$ of (3) and $25 \mathrm{mg}$ for $50 \mu \mathrm{l}$ of (4). All amounts were more than adequate on a mole ratio basis for sampling $\mathrm{NO}_{2}$ over 2 weeks. No effect on sampler performance of aliquot volume of solution (3) was noted. However, use of 50\% TEA in water significantly reduced sampler uptake (by ca. 18\%) compared with 30\% TEA in water. The authors suggested that this may be because of insufficient water availability, but there may also have been an effect of blocking the grids, thereby restricting access of $\mathrm{NO}_{2}$ molecules (25).

In terms of blanks, a better detection limit (60 ppbV.h) was found for direct pipetting of water rather than for dipping in acetone solution (200 ppbV.h). However, in a more recent study using both $20 \%$ and $50 \%$ solutions of TEA in either acetone or water, dipping rather than pipetting was shown to lead to greater precision, especially for $50 \%$ TEA solutions in either acetone or water, with lower measured values from pipetted samples than dipped samples (91). The precision for pipetted solutions at $50 \%$ TEA (whether in water or acetone) was particularly poor. This was ascribed to surface tension effects leading to 'creep' of pipetted solution up the walls of the tube, thereby increasing the effective surface area for capture of $\mathrm{NO}_{2}$. In a detailed laboratory study, the use of 3 meshes evenly coated with $40 \mu \mathrm{l}$ of a $10 \% \mathrm{v} / \mathrm{v}$ solution of TEA in water (with no surfactant) was optimal in terms of precision (51).

Comparisons of different methods across the UK monitoring network have shown similar results. The use of 50\% TEA in acetone gave higher $\mathrm{NO}_{2}$ values than 10 or $20 \%$ TEA in water, which gave higher values than 50\% TEA in water $(83,84,86-88)$. A compilation of 23 Local Authority studies in the UK concluded that there was a seasonal bias (relative to automatic analyzers) in the behaviour of tubes prepared using TEA+water, but not for tubes using TEA+acetone (79). Their overall conclusion matched the conclusions from the national network comparisons, that the performance of diffusion tubes for monitoring $\mathrm{NO}_{2}$ depends more on the laboratory used to prepare and analyse the tubes than on any other single factor. The same 
conclusion was reached following an inter-laboratory comparison in France (80). This study also noted that the commercial supplier of passive diffusion tubes (Gradko International, Winchester, UK) had subtly changed the tube design over a period of years, and that some of the differences noted among laboratories might have come from the (re)use of different designs of tube.

Perhaps the most thorough systematic examination of the different methods of tube preparation, involving 680 duplicated exposures over 146 exposure periods (92), showed that the dipping of grids (rather than manually pipetting a TEA solution) produced greater reproducibility and capture efficiency (expressed as maximised response), regardless of solvent used (acetone, water) or \%TEA in solution. If pipetting was used, then a solution of $20 \%$ TEA in water produced the best performance.

Both UK and French inter-comparison exercises have shown a gradual improvement over the years in accuracy (compared against automatic analyzers) and a gradual reduction in spread across different laboratories, but the differences among laboratories are still large, with no consensus as to the cause.

\section{Conclusion}

There is a clear need for consistency in tube preparation. Problems of reproducibility of the method have been noted in both the UK and in France in inter-lab comparisons. The minimum requirement based on studies to date is that at least 2 grids should be used to support the TEA absorbent, and the use of 50\% solutions of TEA in water should be avoided in favour of weaker solutions, or solutions of TEA in acetone. There is no clear pattern concerning pipetting of the absorbent onto grids pre-inserted into tubes, or dipping grids into a solution before assembling tubes. Different laboratories find one or other method gives smaller variability, probably related to detailed protocols and practice used. It appears, however, that dipping is preferable to manual pipetting of solutions.

\subsection{Tube storage}

Several authors have been concerned over the long-term stability of prepared tubes prior to exposure, and the effects on blank concentrations arising from storage. The original paper (1) gives details showing negligible effects on sampling results when samplers were stored at room temperature for up to 39 days before exposure. There was no consistent pattern over time for tubes analysed after exposure and subsequent storage. Absorption of $\mathrm{NO}_{2}$ by the plastic walls of the tubes and release after tube preparation, leading to an increase in blank levels during storage, has been noted (14, 15)., with blank levels increasing from 7 to $99 \mathrm{ppbV}$.h over a month. A similar rate of increase (34 ppbV.h per week) was seen independently (67) with acrylic tubes, and greater increases with PTFE tubes. Storage in a freezer prevented the increase, suggesting that the increase was not caused by $\mathrm{NO}_{2}$ trapped in the plastic caps. However, in remote areas some exposed samples gave lower readings than capped blanks, implying a contribution to capped tubes from material originally present in the tube materials at the time of preparation. No decomposition of TEA in tubes was observed after 6 weeks of storage (39). Storage of prepared tubes in a refrigerator in a plastic container appears to be optimal (51). 
Tests of the stability of tubes 'spiked' with $\mathrm{NO}_{2}{ }^{-}$, capped and exposed outdoors for up to 2 months, or at $4{ }^{\circ} \mathrm{C}$ in a cold room in the dark showed no loss of $\mathrm{NO}_{2}^{-}$(89). It was suggested that the use of a shield to protect the tubes outdoors had protected the tubes from UV light. In contrast, storage of exposed samplers in the light and at room temperature over 2 months significantly reduced the recovery of $\mathrm{NO}_{2}^{-}$(47).

\section{Conclusion}

Prepared tubes and exposed tubes should be kept in the dark and refrigerated, in sealed containers, before use and after use, before extraction and analysis. In these conditions, storage of up to several months is possible without introduction of large uncertainties, either as variability in the blanks or systematic losses.

\subsection{Tube extraction}

Trapped $\mathrm{NO}_{2}^{-}$has usually been extracted for subsequent analysis using water, or IC eluent. Most often, extraction and colorimetric reaction has been done in the sample tube itself. In the original, and simplest, method (1) the mixed colour reagent (acidified sulphanilamide and NEDA) is added directly to the sample tube. It was noted that adding reagents separately can give unreliable results, because if sulphanilamide is added first, the diazotised product is unstable and may decompose before undergoing the colour-forming reaction with NEDA. This observation may have been overlooked by subsequent users of Palmes tubes, e.g.(17), because of the convenience of storing the colour reagents as two separate solutions (the mixed colour reagent gradually discolours), and may be responsible for the (anecdotal) evidence that changing analysts in the same laboratory can give different results (79). Inefficient extraction of $\mathrm{NO}_{2}^{-}$prior to chemical analysis was identified as a cause of significant under-reading by diffusion tubes compared with automatic analysers in the early years of the UK monitoring network $(81,82)$. Use of a single laboratory for chemical analysis of exposed tubes greatly improved the variability of the technique. The average bias across the network changed from $-11 \%$ to $+13 \%$ between 1994 and 2001 as a result of improvements in extraction (84).

\section{Conclusion}

Care must be taken to ensure adequate extraction of $\mathrm{NO}_{2}^{-}$into solution, and freshlymade pre-mixed reagents should be used for colorimetric analysis.

\subsection{Variations in tube design}

In addition to the subtle changes in the design and construction of commerciallyavailable Palmes-type diffusion tubes (80), there have been several variations on the basic Palmes design over the past 30 years. Problems associated with $\mathrm{NO}_{2}$ absorption on the tube walls were addressed using stainless steel (14) but this suggestion does not appear to have been followed up. Other plastics have been investigated; PTFE showed larger blanks than acrylic tubes (67), presumably because of greater solubility of $\mathrm{NO}_{2}$ in the more porous material. Polypropylene (93) and polyethylene (16) have also been used, and quartz tubes have been used to investigate the effects of UV light during and after sampling (75). Completely shaded (foil-wrapped) or blackened tubes have also been used to investigate the effects of light $(32,33,75)$. Different tube designs have been compared in inter-laboratory comparisons under controlled conditions, and large differences in measured $\mathrm{NO}_{2}$ concentrations were observed, but it is not clear how the differences in tube design affected performance because there were larger 
differences among tubes supposedly of identical 'Palmes' design than for variations (44).

In one study, TEA on a cellulose filter was used as the trapping medium, and a stainless steel grid was use at the sampler entrance to stop wind incursions, but no indication was given of how this affected sampling rates (93).

In order to restrict ingress of turbulent eddies, which could lead to effective shortening of the diffusion path, several studies have used some form of permeable cover on the face of the tube, ranging from grids $(31,73)$ to membranes $(44,51,89$, 94). However, it is not easy to estimate how much such 'wind barriers' also impede the diffusion process by effectively restricting molecular diffusion across the tube inlet. Consequently, the sampling rate cannot be calculated from first principles. Limited tests with two different meshes of grid and an open sampler showed similar uptake rates indoors, but a marked reduction (almost halving) in sampling rate outdoors, which was similar for both mesh sizes (the coarse mesh had 38\% open space, fine had $43 \%$ open space) ( 73 ).

The use of a membrane gave a consistently smaller measurement compared with standard open tubes (89), but it is not clear whether this was because the membrane prevented wind-induced shortening of the diffusion path, prevented within-tube chemical reaction of $\mathrm{NO}$ and $\mathrm{O}_{3}$ because of reactions on the membrane, prevented loss of water (which may restrict uptake at low humidities), or simply added to the diffusion resistance for $\mathrm{NO}_{2}$ molecules. Diffusion, when using a membrane, is controlled by the internal diameter of the tube, rather than by the size of the hole in the cap securing the membrane (51). In a very detailed multi-factorial laboratory experiment with $\mathrm{NO}_{2}$ in the dark, tubes closed by a $1.2 \mathrm{~mm}$ thick PTFE membrane were shown to respond to relative humidity, averaging time and temperature, but only weakly to wind speed $\left(0.8\right.$ to $\left.3.6 \mathrm{~m} \mathrm{~s}^{-1}\right)$ or $\mathrm{NO}_{2}$ concentration (effects $< \pm 2 \%$ ). The effect of temperature was as expected from theory (its effect on the diffusion coefficient of $\mathrm{NO}_{2}$ in air). After evaluation of the absolute effects of the different factors on uptake rates, a simplified expression was obtained for the membranecapped tubes (51):

$$
\text { Uptake rate }\left(\mathrm{cm}^{3} \mathrm{~h}^{-1}\right)=42.9+8.9 \ln \left[\mathrm{H}_{2} \mathrm{O}\right]
$$

The absolute sampling rate is similar to that for a standard Palmes tube $\left(60 \mathrm{~cm}^{3} \mathrm{~h}^{-1}\right.$ at $50 \% \mathrm{RH}$ and $20^{\circ} \mathrm{C}$, cf. $55 \mathrm{~cm}^{3} \mathrm{~h}^{-1}$ for a standard Palmes tube - see above, (Section 2.1). However, the authors do not state the actual dimensions of the tubes used, so it is not possible to compare directly the effect of the membrane on the sampling rate.

There was a small decrease in uptake measured after the first week's exposure, which was attributed to the loss of water vapour from the TEA as noted earlier (39). Field testing showed that the use of the above equation gave results within $25 \%$ of those from an automatic sampler, but better agreement was found using a more complex equation with explicit inclusion of temperature, sampling time, relative humidity and wind speed. No contribution from within-tube chemistry was observed, but would have been likely to be small at the monitoring site, which is remote from sources of NO. This method has been formally demonstrated to be equivalent to the reference method for the $1^{\text {st }}$ European Daughter Directive, an annual limit value of $40 \mu \mathrm{g} \mathrm{m}^{-3}$ 
(95), but does require measurements of the temperature, relative humidity and average wind speed at the sampling location in order to determine the sampling rate.

\section{Conclusion}

The use of grids or membranes across the tube entrance would prevent problems associated with turbulence, and may prevent the systematic positive bias caused by chemical reaction of $\mathrm{NO}$ with $\mathrm{O}_{3}$ inside the tube. However, there are no clear data on the effects of such grids or membranes on sampling rates that could be used to assess whether calibration would be required for use in the field. Direct comparisons with automatic analyzers in the field suggest that the results are not significantly less reliable than those obtained using open tubes.

\subsection{Other designs of passive samplers}

Although the above modifications have involved relatively straightforward changes to the basic Palmes design, passive samplers of very different design and sampling rates have also been used to measure $\mathrm{NO}_{2}$ concentrations in air (96). The more radical changes have involved shortening of the diffusion path, even to the point of a badgetype sampler where the exposed diameter is much greater than the diffusion path length, and a membrane is used to avoid the effects of wind turbulence (much more important for short path lengths). Where experiments involving alternative designs have helped in the evaluation of the many different factors that affect the Palmes design, they have been cited above. Although short path samplers have very much faster sampling rates (e.g. $50 \mathrm{~cm}^{3} \mathrm{~min}^{-1}$ rather than $50 \mathrm{~cm}^{3} \mathrm{~h}^{-1}$ ), and therefore can provide higher time resolution, they do require a degree of turbulence to ensure that air close to the sampler is not depleted in $\mathrm{NO}_{2}$. This usually requires wind speeds at the sampler face in excess of $0.6 \mathrm{~m} \mathrm{~s}^{-1}$. Examples of different sampler types are shown in Table 1.

\section{Validation of diffusion tube methods}

The validity of passive diffusion sampling for measuring $\mathrm{NO}_{2}$ ultimately depends on the precision and accuracy with which laboratory, and especially field, measurements correspond with accepted active measurement techniques or reference concentrations. The reference method for $\mathrm{NO}_{2}$ is usually the chemiluminescent reaction of $\mathrm{NO}$ with $\mathrm{O}_{3}$, where the $\mathrm{NO}$ is generated from $\mathrm{NO}_{2}$ by thermal catalysis (usually on a molybdenum convertor). Although this is an approved reference method, it is not free from artefacts - as noted above, PAN and HONO would be expected to give $100 \%$ positive interferences $(97,98)$, and the response of the instrument, usually calibrated in dry air, is dependent on water vapour in the sampled atmosphere $(44,99)$. Standardised methodologies for conducting laboratory and field validation of passive samplers have been developed (e.g. (3)); procedures for comparing $\mathrm{NO}_{2}$ passive samplers with automated continuous samplers have been developed for use across the European Union (100). For the UK, the need for a validated reference method has already been noted (Section 1, (9)).

\subsection{Laboratory comparisons}

Experiments in carefully controlled laboratory conditions have been widely used in evaluating the calibration and validation of passive diffusion samplers for $\mathrm{NO}_{2}$. Factors such as temperature, humidity and wind speed (turbulence) are regulated, at one or more fixed concentrations of $\mathrm{NO}_{2}$ (measured using an automatic monitor or 
generated from a known and calibrated source), over a sampling period of up to several days. Measurements are usually made in the dark, and with no other reactive trace gases present. Details of experiments to study effects of humidity and wind speed are given above.

Results are summarised in Table 2 and show the large range of responses that can be obtained if several different laboratories and tube preparation techniques are used, even in well-controlled conditions. Both under-sampling and over-sampling compared with theory are seen.

\subsection{Indoor comparisons}

Passive diffusion sampling for $\mathrm{NO}_{2}$ has been used indoors to investigate effects on human health. Under these conditions, turbulence caused by wind is not a problem indeed there may be the risk of an effective lengthening of the diffusion path because of depletion of $\mathrm{NO}_{2}$ near the tube entrance. This is likely to be small for standard Palmes-type tubes, because the sampling rate is slow. Effects of sunlight are also likely to be small indoors, as are reactions between $\mathrm{O}_{3}$ and NO. There may be cosampling of HONO from gas-burning stoves and cookers, but any comparison with a chemiluminescent automatic sampler using thermal conversion of $\mathrm{NO}_{2}$ to $\mathrm{NO}$ would include the sum of $\mathrm{NO}_{2}$ and $\mathrm{HONO}$ in both cases. The biggest problem indoors is the lack of turbulent mixing, and large spatial variability. Although this makes the use of many low-cost samplers attractive, direct comparison with a single fixed-point automatic monitor becomes more difficult. Results from some indoor comparisons of Palmes-type diffusion tubes with automatic monitors are shown in Table 3.

\subsection{Outdoor comparisons}

Most of the controlled comparisons of passive diffusion samplers have been against chemiluminescent monitors under field conditions, with sampling periods of between 1 and 4 weeks. The sampling duration appears to have an effect on the absolute concentrations determined, even in comparisons of identical diffusion tubes colocated and sampled with different frequencies (see above, Section 4.2). For that reason, data on outdoor comparisons are presented in terms of sampling duration in Tables 4-6 and Figures 4-6. It should be borne in mind that the accuracy of automatic monitors for $\mathrm{NO}_{2}$ has been estimated at $\pm 3.5 \mathrm{ppbV}$ or $\pm 10 \%$ (101).

\section{Conclusion}

As illustrated in Tables 4-6 and Figures 4-6, there is general good agreement between the concentrations of $\mathrm{NO}_{2}$ measured using diffusion tubes and concentrations measured using chemiluminescent analyzers under field conditions. However, the data also reflect the large spread of responses found by different authors using slightly different methods under a range of conditions. In general, the degree of positive bias decreases from 1 week to 2 week exposures, but there is still a large positive bias shown for some data sets where tubes have been exposed over 4 weeks. It should be noted that some of the data refer to relatively short periods of comparison, whereas others extend over several sites and years, so they should not all be given equal weight. 


\section{Use of passive diffusion tubes for $\mathrm{NO}_{2}$ concentration monitoring}

Passive diffusion tubes of the Palmes design, and several variants, have been widely used in the United Kingdom and Europe for monitoring the spatial and temporal variations in concentration of $\mathrm{NO}_{2}$. A summary of published data is given in Table 7 . This is a fairly comprehensive list of published results for the U.K., with additional references to monitoring elsewhere that is relevant to the use of the technique. It should be noted that there has been extensive use of the Palmes-type tube in by local authorities in France, with data published as internal reports or on the web. Only peerreviewed papers are cited here. Table 7 does not include measurements made specifically as part of method validation - only reports with significant spatial or temporal extent, or with an original application of the technique, are included. The scope of UK Local Authority participation (not necessarily published, or included in Table 7) can be judged by reference to the UK Network Instruction Manual, which lists 50 laboratories (102). New guidance has been provided recently, following an extensive review of passive diffusion tube monitoring in the UK (103). In addition to the studies listed in Table $7, \mathrm{NO}_{2}$ concentrations are also measured using passive diffusion tubes at 3 sites in the Level II network for Forest Health Monitoring operated by UK Forest Research (http://www.forestresearch.gov.uk/pdf/Level_II data_collection.pdf/

\$FILE/Level_II data collection.pdf) and at the 10 terrestrial sites of the Environmental Change Network (http://www.ecn.ac.uk/Database/get sandm.asp? $\underline{\mathrm{st}=\mathrm{T}}$ ). 


\section{Conclusions}

Passive diffusion tubes of the Palmes type have been widely used in the UK and Europe to measure $\mathrm{NO}_{2}$ concentrations. The method is simple, cheap and easy to use, and is a very useful tool for measuring spatial and temporal variations. However, the absolute concentrations obtained using this method can show large deviations from more expensive automatic methods, particularly in urban areas and close to roads, which is where the use of tubes may be of greatest interest in determining where Air Quality Targets are most likely to be exceeded. Under such conditions, the tubes show a positive bias, and so give a conservative estimate of actual air concentrations, but may provide useful relative values for comparing different locations. The reasons for the positive bias are understood, and relate to inhomogeneities in the sampled air close to sources of NO.

It has also become clear through many investigations and inter-laboratory comparisons that the details of tube construction, assembly, exposure, extraction and analysis play a major role in controlling the variability of the method. Many different variants have been used, and it appears that small changes (for example, in the way in which the absorbent is placed on the supporting grids) can have large systematic effects on the measured concentrations. Although considerable progress has been made in both the UK and France in reducing inter-laboratory variation, it is not clear why large differences still remain.

Effects of environmental conditions during sampling have been investigated. The effects of temperature on the diffusion of $\mathrm{NO}_{2}$ molecules are predictable, and affect the sampling rate. These can be corrected for, but only contribute to variation of a few percent. Humidity also affects the response when triethanolamine is used as the absorbent; the dependence is relatively weak at normal ambient UK temperatures, but becomes important when absolute humidities are small, i.e. in cold, dry air, or very high (at high temperatures and high relative humidity). The dependence of sampling rate on wind speed and turbulence has been demonstrated unequivocally in the laboratory, leading to increasing positive bias as wind speed increases. However, there is a much less clear response when sampling outdoors; there is no predictable relationship between wind speeds measured at a site and the actual turbulence conditions near the open end of the sampler.

The use of a membrane or an inert grid at the entrance to the tube appears to reduce the effect of turbulence, but may reduce the sampling rate; this might require calibration of the tubes, rather than relying simply on the tube geometry to calculate sampling rates from first principles. However, there are also indications that a membrane at the tube entrance prevents the within-tube reactions of $\mathrm{NO}$ with $\mathrm{O}_{3}$, which would lead to positive bias at sites close to NO sources. This may be because of the solubility of NO in PTFE, but no study of the phenomenon has been made.

Sampling times vary between a few days up to 2 months. There is a systematic decrease in the effective sampling rate over periods of a week or more. This has masked the positive bias in some of the studies where tubes have been exposed for 4 weeks, leading to better agreement with automatic analyzers than might have been expected. Exposure to light and to high temperatures appears to be responsible. 
Published in Crit Rev Anal Chem 39(4), 289-310, 2009

9. References 
Table 1. Summary of different designs of passive sampler used for measurement of $\mathrm{NO}_{2}$ (see also Tang et al. $2001{ }^{8}$, Yu et al., $2008{ }^{96}$ )

\begin{tabular}{|c|c|c|c|c|}
\hline $\begin{array}{l}\text { Diffusion } \\
\text { length }\end{array}$ & $\begin{array}{l}\text { Absorbent } \\
\text { for } \mathrm{NO}_{2}\end{array}$ & $\begin{array}{l}\text { Sampling rate } \\
\text { for } \mathrm{NO}_{2}\end{array}$ & membrane & ref \\
\hline $\mathrm{n} / \mathrm{a}$ & $\begin{array}{l}\text { glass fibre } \\
\text { dipped in } 9 \% \\
\text { TEA in } \\
\text { acetone }\end{array}$ & $\begin{array}{l}112 \mathrm{~cm}^{3} \mathrm{~min}^{-1} \\
\text { at room } \\
\text { temperature }\end{array}$ & $\begin{array}{l}0.8 \mu \mathrm{m} \text { pore size } \\
\text { polycarbonate membrane }\end{array}$ & $(48)$ \\
\hline $\begin{array}{l}\text { ca. } 1 \mathrm{~cm}(\text { not } \\
\text { defined) }\end{array}$ & $\begin{array}{l}\text { Glass fibre } \\
\text { with } 1.68 \mathrm{M} \\
\text { TEA in } \\
\text { acetone }(0.5 \\
\text { ml on } 33 \mathrm{~mm} \\
\text { diameter }) \\
\end{array}$ & $154 \mathrm{~cm}^{3} \min ^{-1}$ & $\begin{array}{l}\text { Diffusion barriers - mesh } \\
\text { and perforated discs }\end{array}$ & $\begin{array}{l}78 \\
104)\end{array}$ \\
\hline $10 \mathrm{~mm}$ & $\begin{array}{l}\mathrm{NaI} / \mathrm{Na} \\
\text { arsenite on } \\
\text { paper filter }\end{array}$ & $25 \mathrm{~cm}^{3} \min ^{-1}$ & $\begin{array}{l}\text { PTFE membrane and } \\
\text { stainless steel screen }\end{array}$ & $(105)$ \\
\hline $7 \mathrm{~mm}$ & $\begin{array}{l}\mathrm{n} / \mathrm{a} \\
\text { (toluene) }\end{array}$ & $\begin{array}{l}\text { ca. } 70 \mathrm{~cm}^{3} \\
\mathrm{~min}^{-1} \\
\end{array}$ & $\begin{array}{l}\text { Various stainless steel } \\
\text { meshes }\end{array}$ & (37) \\
\hline $10 \mathrm{~mm}$ & $\begin{array}{l}\text { Paper filter } \\
\text { with } 20 \% \\
\text { TEA in water } \\
(0.1 \mathrm{ml} \text { on } 25 \\
\text { mm diameter }) \\
\text { or SS grids } \\
\text { dipped in } 10 \% \\
\text { TEA in } \\
\text { acetone }\end{array}$ & $\begin{array}{l}\text { ca. } 20 \mathrm{~cm}^{3} \\
\min ^{-1}\end{array}$ & Polypropylene fibre & (72) \\
\hline $10-87 \mathrm{~mm}$ & $\begin{array}{l}\mathrm{NaI} / \mathrm{NaOH} \text { in } \\
\text { methanol on } \\
\text { paper filter }\end{array}$ & $25 \mathrm{~cm}^{3} \mathrm{~min}^{-1}$ & $\begin{array}{l}\text { PTFE membrane and } \\
\text { stainless steel screen }\end{array}$ & (20) \\
\hline $\begin{array}{l}\text { Cylindrical } \\
\text { ca. } 4 \mathrm{~mm} \\
\text { 'Radiello' }\end{array}$ & $\begin{array}{l}\text { TEA on } \\
\text { cartridge }\end{array}$ & $62 \mathrm{~cm}^{3} \min ^{-1}$ & Polyethylene membrane & $(36)$ \\
\hline $60 \mathrm{~mm}$ & $\begin{array}{l}\text { TEA on } \\
\text { plastic } \\
\text { membrane } \\
\end{array}$ & ca. $3 \mathrm{~cm}^{3} \mathrm{~min}^{-1}$ & Cotton membrane & $(106)$ \\
\hline $\mathrm{n} / \mathrm{a}$ & $\begin{array}{l}\text { Proprietary on } \\
\text { filter }\end{array}$ & $9.5 \mathrm{~cm}^{3} \min ^{-1}$ & Diffuser & (107) \\
\hline $73 \mathrm{~mm}$ & TEA & $0.83 \mathrm{~cm}^{3} \mathrm{~min}^{-1}$ & $\begin{array}{l}\text { Glass frit, } 160-250 \mu \mathrm{m} \\
\text { pore, } 3 \mathrm{~mm} \text { thick }\end{array}$ & $(108)$ \\
\hline $39.8 \mathrm{~mm}$ & $\begin{array}{l}\text { TEA on glass } \\
\text { fibre filter }\end{array}$ & $2.5 \mathrm{~cm}^{3} \mathrm{~min}^{-1}$ & Stainless steel mesh & $(109)$ \\
\hline $\mathrm{n} / \mathrm{a}$ & TEA on paper & $16 \mathrm{~cm}^{3} \mathrm{~min}^{-1}$ & Sintered polyethylene & $(110)$ \\
\hline
\end{tabular}


Table 2. Summary of laboratory comparisons of Palmes-type diffusion tubes (DT) for $\mathrm{NO}_{2}$ with automatic continuous monitors (AM) or known predetermined $\mathrm{NO}_{2}$ concentrations

\begin{tabular}{|l|l|l|l|l|}
\hline $\begin{array}{l}\text { Conc } \\
(\mathrm{ppb})\end{array}$ & Conditions & $\begin{array}{l}\text { Comparison } \\
\mathrm{R}=\text { ratio meas:theory } \\
(\mathrm{DT})=\mathrm{a} .(\mathrm{AM})+\mathrm{b}\end{array}$ & Comments & Ref \\
\hline & & $\mathrm{R}=1.0$ & Range $0-30$ ppmh & $(1)$ \\
\hline 160 & $\begin{array}{l}\text { Varying } \mathrm{RH}, \\
5-85 \%\end{array}$ & $\begin{array}{l}\mathrm{R}=0.78+ \\
0.0025 \times \mathrm{RH}(\%)\end{array}$ & Low wind speed 'starvation' & $(50)$ \\
\hline $5-30$ & Varying RH & $\mathrm{DT}=0.70 \mathrm{AM}+3.65$ & No sig. effect $\mathrm{RH}$ & $(28)$ \\
\hline $\begin{array}{l}100-1 \\
100\end{array}$ & $\begin{array}{l}\text { Varying } \\
\text { turbulence }\end{array}$ & $\mathrm{R}=1.0$ & $\begin{array}{l}4 \mathrm{~m} \mathrm{~s}^{-1} \text { wind increased to } \\
\mathrm{R}=1.48\end{array}$ & $(47)$ \\
\hline 180 & Varying T & $\mathrm{R}=1.0$ above $-8{ }^{\circ} \mathrm{C}$ & Decreased $<-8{ }^{\circ} \mathrm{C}$ & $(43)$ \\
\hline $23-26$ & $\begin{array}{l}21{ }^{\circ} \mathrm{C}, \\
65-70 \% \mathrm{RH}\end{array}$ & $\mathrm{R}=0.8$ to 1.4 & $\begin{array}{l}\mathrm{R} \text { depends on tube } \\
\text { preparation method }\end{array}$ & $(86)$ \\
\hline 41 & $\begin{array}{l}25^{\circ} \mathrm{C}, 75 \% \mathrm{RH} \\
{ }^{\circ} \mathrm{C}, 30 \% \mathrm{RH}\end{array}$ & $\begin{array}{l}\mathrm{R}=1.3 \text { to } 1.8 \\
\mathrm{R}=0.75 \text { to } 1.06\end{array}$ & $\begin{array}{l}\text { Palmes tubes only; others } \\
\text { used in study }\end{array}$ & $(44)$ \\
\hline 22 & $25^{\circ} \mathrm{C}, 75 \% \mathrm{RH}$ & $\mathrm{R}=0.77$ to 1.29 & $\begin{array}{l}\text { several labs and prepn } \\
\text { methods }\end{array}$ & $(80)$ \\
\hline 36 & $20^{\circ} \mathrm{C}, 50 \% \mathrm{RH}$ & $\mathrm{R}=1.0$ to 1.8 & $\begin{array}{l}\text { Incr. with wind speed } 0.2 \text { - } \\
2.3 \text { m s }{ }^{-1}\end{array}$ & $(26)$ \\
\hline 105 & & & \\
\hline
\end{tabular}

Table 3. Summary of indoor comparisons of Palmes-type diffusion tubes (DT) for $\mathrm{NO}_{2}$ with automatic continuous monitors (AM)

\begin{tabular}{|l|l|l|l|l|}
\hline $\begin{array}{l}\text { Conc } \\
(\mathrm{ppb})\end{array}$ & Conditions & $\begin{array}{l}\text { Comparison } \\
\mathrm{R}=\text { ratio meas:theory } \\
(\mathrm{DT})=\mathrm{a} .(\mathrm{AM})+\mathrm{b}\end{array}$ & Comments & Ref \\
\hline 137 & 5 days & $\begin{array}{l}\mathrm{R}=1.06 \text { (kitchen) } \\
\mathrm{R}=0.85\end{array}$ & duplicate tubes & $(111)$ \\
7 & & $\begin{array}{l}\mathrm{R}=0.7 \text { (bedrooms) } \\
\mathrm{R}=1.3 \text { (kitchens) }\end{array}$ & $\begin{array}{l}\text { duplicate } \\
\text { Data recalc }\end{array}$ & $(50)$ \\
\hline $7-95$ & $3-12$ days in 9 homes & & \\
\hline
\end{tabular}


Published in Crit Rev Anal Chem 39(4), 289-310, 2009

Table 4. Summary of outdoor comparisons of Palmes-type diffusion tubes (DT) for $\mathrm{NO}_{2}$ exposed for 1 week or less with automatic continuous monitors (AM)

\begin{tabular}{|c|c|c|c|c|}
\hline $\begin{array}{l}\text { Conc } \\
(\mathrm{ppb})\end{array}$ & Conditions & $\begin{array}{l}\text { Comparison } \\
\mathrm{R}=\text { ratio meas:theory } \\
(\mathrm{DT})=\mathrm{a} .(\mathrm{AM})+\mathrm{b}\end{array}$ & Comments & Ref \\
\hline $4-60$ & Rural UK & $\mathrm{DT}=0.97 \mathrm{AM}+1.0$ & No effect of windspeed or T & $(17)$ \\
\hline $13-38$ & Netherlands & $\mathrm{R}=0.99$ & & $(50)$ \\
\hline $1-6$ & $\begin{array}{l}\text { Sweden, } \\
\text { remote }\end{array}$ & $\mathrm{DT}=1.36 \mathrm{AM}-0.60$ & $\begin{array}{l}\text { Also compared with active } \\
\text { TEA and DOAS }\end{array}$ & $(67)$ \\
\hline $6-37$ & $\begin{array}{l}\text { Rural Italy, } \\
\text { EMEP site }\end{array}$ & $\mathrm{DT}=0.72 \mathrm{AM}+0.5$ & & (7) \\
\hline $20-47$ & Urban UK & $\begin{array}{l}\mathrm{R}=1.27 \pm 0.10 \\
\text { (acrylic tube) } \\
\mathrm{R}=1.06 \pm 0.09 \\
\text { (quartz tuibe) }\end{array}$ & $\begin{array}{l}\text { Overread attributed to } \\
\text { chemistry in tube }\end{array}$ & $(75)$ \\
\hline $12-33$ & Urban UK & $\begin{array}{l}\mathrm{R}=1.24 \\
\text { (range 0.95-1.72) }\end{array}$ & $\begin{array}{l}\text { cf. } 2 \text { week and } 4 \text { week } \\
\text { sampling }\end{array}$ & (19) \\
\hline $1-30$ & $\begin{array}{l}\text { Rural \& urban } \\
\text { UK }\end{array}$ & $\mathrm{DT}=1.39 \mathrm{AM}+2.0$ & $\begin{array}{l}\text { Values }<10 \text { ppb were close } \\
\text { to } 1: 1\end{array}$ & $(89)$ \\
\hline $16-30$ & $\begin{array}{l}\text { Urban UK } \\
12 \text { sites }\end{array}$ & $\mathrm{R}$ range 1.0 to 1.61 & $\begin{array}{l}\text { Compilation of local } \\
\text { authority data }\end{array}$ & (79) \\
\hline $12-40$ & Roadside UK & $\begin{array}{l}\mathrm{R} \text { range } 0.7 \text { to } 2.0 \\
\text { Mean } \mathrm{R}=1.31\end{array}$ & & $(112)$ \\
\hline 25 & Airport UK & $\mathrm{R}=2.0$ & Limited data set & $(113)$ \\
\hline $15-50$ & Edinburgh & $\begin{array}{l}\mathrm{R}=1.32(\mathrm{n}=587) \\
\text { (range } 1.18 \text { to } 1.41)\end{array}$ & 3 sites, 8 prepn methods & $(91)$ \\
\hline $24-38$ & $\begin{array}{l}\text { US-Mexico } \\
\text { urban }\end{array}$ & $\begin{array}{l}\mathrm{DT}=1.62 \mathrm{AM}-22.5 \\
\text { (calc from data) }\end{array}$ & $\begin{array}{l}4 \text { sites; overread increased } \\
\text { with } \mathrm{NO}_{2}: \mathrm{NO}_{\mathrm{x}} \text { ratio }\end{array}$ & $(34)$ \\
\hline
\end{tabular}


Table 5. Summary of outdoor comparisons of Palmes-type diffusion tubes (DT) for $\mathrm{NO}_{2}$ exposed for 2 weeks with automatic continuous monitors (AM)

\begin{tabular}{|c|c|c|c|c|}
\hline $\begin{array}{l}\text { Conc } \\
(\mathrm{ppb})\end{array}$ & Conditions & $\begin{array}{l}\text { Comparison } \\
\mathrm{R}=\text { ratio meas:theory } \\
(\mathrm{DT})=\mathrm{a} .(\mathrm{AM})+\mathrm{b}\end{array}$ & Comments & Ref \\
\hline $7-28$ & $\begin{array}{l}\text { Rural Italy, } \\
\text { EMEP site }\end{array}$ & $\mathrm{DT}=0.80 \mathrm{AM}-1.3$ & & (7) \\
\hline $10-38$ & $\begin{array}{l}\text { UK Urban } \\
\text { background }\end{array}$ & $\begin{array}{l}\mathrm{R}=1.09 \pm 0.02 \\
\text { (normal) } \\
\mathrm{R}=0.91 \pm 0.02 \\
\text { (sheltered) }\end{array}$ & $\begin{array}{l}17 \text { sites, } 1 \text { year; } \\
\text { no diff. summer/winter }\end{array}$ & $\begin{array}{l}(32, \\
33)\end{array}$ \\
\hline $\begin{array}{l}18-27 \\
7-22 \\
7-17\end{array}$ & $\begin{array}{l}\text { Amsterdam } \\
\text { Huddersfield } \\
\text { Prague }\end{array}$ & $\begin{array}{l}\mathrm{R}=1.16 \\
\mathrm{R}=1.03 \\
\mathrm{R}=0.99\end{array}$ & $\begin{array}{l}\text { Compared with badge type } \\
\text { also. Only one mesh }\end{array}$ & $(90)$ \\
\hline $15-29$ & Urban UK & $\begin{array}{l}\mathrm{R}=1.15 \\
\text { (range 0.91-1.47) }\end{array}$ & $\begin{array}{l}\text { cf. } 1 \text { week and } 4 \text { week } \\
\text { sampling }\end{array}$ & (19) \\
\hline $18-30$ & Rome & R range 0.4 to 1.4 & Poor correlation & $(47)$ \\
\hline $13-50$ & Urban UK & $\begin{array}{l}\mathrm{R} \text { range } 0.94 \text { to } 1.02 \\
\mathrm{R} \text { range } 0.76 \text { to } 0.91\end{array}$ & $\begin{array}{l}20 \% \text { TEA:water } \\
50 \% \text { TEA:water }\end{array}$ & (39) \\
\hline $15-32$ & Urban UK & $\begin{array}{l}\mathrm{R}=1.16 \pm 0.05 \text { (out) } \\
\mathrm{R}=1.03 \pm 0.06 \text { (in) }\end{array}$ & $\begin{array}{l}\text { Effect of shelter; } \\
\text { R decr as } \mathrm{NO}_{2} \text { incr }\end{array}$ & $(21)$ \\
\hline $24-30$ & $\begin{array}{l}\text { Urban UK } \\
5 \text { sites }\end{array}$ & $\mathrm{R}$ range 0.97 to 1.34 & $\begin{array}{l}\text { Compilation of local } \\
\text { authority data }\end{array}$ & (79) \\
\hline $\begin{array}{l}22 \\
7\end{array}$ & $\begin{array}{l}\text { Urban, Paris } \\
\text { Rural, Paris }\end{array}$ & $\begin{array}{l}\mathrm{R} \text { range } 0.97 \text { to } 1.13 \\
\mathrm{R} \text { range } 0.82 \text { to } 0.93\end{array}$ & Different laboratories & (44) \\
\hline $6-26$ & Urban, Paris & $\begin{array}{l}\mathrm{DT}=0.94 \mathrm{AM}+3.0 \\
\mathrm{R}=0.87 \text { (no shield) } \\
\mathrm{DT}=0.94 \text { AM }-0.5 \\
\mathrm{R}=0.93 \text { (shielded) }\end{array}$ & 4 sites, 13 months & (26) \\
\hline $\begin{array}{l}7 \\
22 \\
\end{array}$ & $\begin{array}{l}\text { Rural Italy } \\
\text { Urban Italy }\end{array}$ & $\begin{array}{l}\mathrm{R}=0.74 \text { to } 0.79 \\
\mathrm{R}=0.92 \text { to } 0.97\end{array}$ & Effect of shelter & (27) \\
\hline $\begin{array}{l}23-29 \\
11-19\end{array}$ & $\begin{array}{l}\text { Urban, } \\
\text { Belgium }\end{array}$ & $\begin{array}{l}\mathrm{R}=0.72 \text { to } 0.82 \\
\mathrm{R}=0.62 \text { to } 1.0\end{array}$ & $\begin{array}{l}\text { Comparison with different } \\
\text { types }\end{array}$ & $(114)$ \\
\hline
\end{tabular}


Table 6. Summary of outdoor comparisons of Palmes-type diffusion tubes (DT) for $\mathrm{NO}_{2}$ exposed for 4 weeks or more with automatic continuous monitors (AM)

\begin{tabular}{|c|c|c|c|c|}
\hline $\begin{array}{l}\text { Conc } \\
(\mathrm{ppb})\end{array}$ & Conditions & $\begin{array}{l}\text { Comparison } \\
\mathrm{R}=\text { ratio meas:theory } \\
(\mathrm{DT})=\mathrm{a} .(\mathrm{AM})+\mathrm{b}\end{array}$ & Comments & Ref \\
\hline \multirow[t]{2}{*}{$4-60$} & $\begin{array}{l}\text { Rural and } \\
\text { Urban UK }\end{array}$ & $\mathrm{R}=1.26$ & sites mostly sheltered & $\begin{array}{l}(11 \\
5)\end{array}$ \\
\hline & Berlin roadside & $\begin{array}{l}\text { Sig. deviation from 1:1 } \\
\text { at some sites }\end{array}$ & DT suitable for screening & $\begin{array}{l}(29 \\
{ }^{2}\end{array}$ \\
\hline $12-40$ & $\begin{array}{l}\text { UK Urban } \\
\text { background }\end{array}$ & $\begin{array}{l}\mathrm{R}=1.08 \pm 0.06 \\
\text { (normal) } \\
\mathrm{R}=0.90 \pm 0.02 \\
\text { (sheltered) }\end{array}$ & $\begin{array}{l}17 \text { sites, } 1 \text { year; } \\
\text { no diff. summer/winter }\end{array}$ & (32) \\
\hline \multirow[t]{2}{*}{$6-25$} & $\begin{array}{l}\text { Various, } 25 \\
\text { sites, Denmark } \\
\text { \& Italy }\end{array}$ & $\mathrm{DT}=1.13 \mathrm{AM}-3.4$ & Wind shield used & )$^{(64}$ \\
\hline & $\begin{array}{l}\text { Urban } \\
\text { background }\end{array}$ & $\begin{array}{l}\mathrm{R}=1.02 \\
\text { (range } 0.61 \text { to } 1.58 \text { ) }\end{array}$ & $\begin{array}{l}38 \text { laboratories } \\
\text { Aug-Oct } 1998\end{array}$ & $\begin{array}{l}(81 \\
\end{array}$ \\
\hline 19 & $\begin{array}{l}\text { Urban } \\
\text { background }\end{array}$ & $\begin{array}{l}\mathrm{R}=0.93 \\
\text { (range } 0.69 \text { to } 1.24 \text { ) }\end{array}$ & $\begin{array}{l}33 \text { laboratories } \\
\text { Aug } 1999\end{array}$ & $(82$ \\
\hline $17-28$ & Urban UK & $\begin{array}{l}\mathrm{R}=1.06 \\
\text { (range 0.88-1.39) }\end{array}$ & $\begin{array}{l}\text { cf. } 1 \text { week and } 2 \text { week } \\
\text { sampling }\end{array}$ & $(19$ \\
\hline \multirow[t]{2}{*}{$16-53$} & $\begin{array}{l}\text { Suburban and } \\
\text { roadside UK }\end{array}$ & $\mathrm{R}=1.36$ & 3 months Sep-Dec & )$^{(18}$ \\
\hline & Rural Denmark & $\begin{array}{rr}\mathrm{DT}=1.15 \mathrm{AM}-0.98 \\
( \pm 0.04) \quad( \pm 0.42)\end{array}$ & 7 monthly data points & (43 \\
\hline 20 & $\begin{array}{l}\text { Urban } \\
\text { background }\end{array}$ & $\begin{array}{l}\mathrm{R}=1.18 \\
\text { (range } 0.80 \text { to } 1.66 \text { ) }\end{array}$ & $\begin{array}{l}31 \text { laboratories } \\
\text { Oct } 2000\end{array}$ & )$^{(83}$ \\
\hline 20 & $\begin{array}{l}\text { Urban } \\
\text { background }\end{array}$ & $\begin{array}{l}\mathrm{R}=1.14 \\
\text { (range } 0.53 \text { to } 1.50 \text { ) }\end{array}$ & $\begin{array}{l}28 \text { laboratories } \\
\text { Sep-Oct } 2001\end{array}$ & $(84$ \\
\hline $2-24$ & $\begin{array}{l}\text { Rural \& urban } \\
\text { UK }\end{array}$ & $\mathrm{DT}=1.41 \mathrm{AM}-1.6$ & $\begin{array}{l}\text { Values }<10 \mathrm{ppb} \text { were } \\
\text { close to } 1: 1\end{array}$ & $\begin{array}{l}(89 \\
)^{2}\end{array}$ \\
\hline $3-22$ & $\begin{array}{l}\text { Rural \& urban } \\
\text { UK }\end{array}$ & $\begin{array}{l}\mathrm{DT}=1.38 \mathrm{AM}-1.9 \\
(2 \text { month exposure })\end{array}$ & $\begin{array}{l}\text { Values }<10 \text { ppb were } \\
\text { close to } 1: 1\end{array}$ & $\begin{array}{l}(89 \\
\end{array}$ \\
\hline $11-35$ & $\begin{array}{l}\text { Urban \& } \\
\text { roadside } \\
16 \text { sites } \\
\end{array}$ & $\begin{array}{l}\mathrm{R} \text { range } 0.49 \text { to } 0.93 \\
\text { (Gradko) } \\
\mathrm{R} \text { range } 0.62 \text { to } 1.42\end{array}$ & $\begin{array}{l}\text { Compilation of local } \\
\text { authority data }\end{array}$ & $\begin{array}{l}(79 \\
)\end{array}$ \\
\hline 20 & Motorway UK & $\mathrm{R}$ up to 1.4 & 3-week sampling & (77 \\
\hline
\end{tabular}


Table 7. Monitoring studies using Palmes-type passive diffusion tubes for the measurement of $\mathrm{NO}_{2}$ concentrations

\begin{tabular}{|c|c|c|}
\hline \multicolumn{3}{|r|}{ United Kingdom } \\
\hline First author (year) & Ref & Comments \\
\hline Colls, 1986 & $(116)$ & Spatial variation within cereal canopy \\
\hline Longhurst, 1987 & $(117)$ & Greater Manchester, several years, $>14$ sites \\
\hline Laxen, 1987 & $(118)$ & Urban, spatial variation in street canyon \\
\hline Campbell, 1988 & $(119)$ & Rural UK, 8 sites, 1985-1987 \\
\hline Goldstein, 1979 & $(120)$ & Indoor vs outdoor, Middlesbrough \\
\hline Ashenden, 1989 & $(121)$ & Rural Wales, 50 sites, 1986 \\
\hline Bower, 1989 & $(122)$ & Urban UK, 1987 \\
\hline $\begin{array}{l}\text { Bower, } 1989 \\
\text { Bower, } 1991 \\
\end{array}$ & $\begin{array}{c}(123, \\
124) \\
\end{array}$ & Urban UK, Jul-Dec 1986, 363 sites \\
\hline Melia, 1978 & $(125)$ & Indoors, gas vs electric cookers \\
\hline Hewitt, 1991 & $(126)$ & Lancaster UK, spatial variation \\
\hline Atkins, 1992 & $(127)$ & W.Europe 1989-1990 \\
\hline Campbell, 1994 & $(115)$ & Urban UK, Jul-Dec 1991, 363 sites \\
\hline Atkins, 1995 & $(128)$ & Rural UK 24 sites 1987-1990 \\
\hline Ashenden, 1995 & $(129)$ & Rural Wales, 23 sites \\
\hline Humfrey, 1996 & $(130)$ & $\begin{array}{l}\text { Literature review of indoor exposure relative to } \\
\text { health, includes world-wide data }\end{array}$ \\
\hline Smith, 1997 & $(131)$ & Rural UK, 12 sites \\
\hline Bell, 1997 & $(132)$ & Rural N. Wales, roadside \\
\hline Smith, 1997 & $(131)$ & Rural UK, 1995, 12 sites \\
\hline Kirby, 1998 & $(133)$ & Urban, Cambridge, local variability \\
\hline Lebret, 2000 & $(134)$ & Huddersfield and 3 other European cities; spatial \\
\hline Hargreaves, 2000 & $(135)$ & Rothamsted, 13 sites, seasonal/spatial variation \\
\hline Hughes, 2000 & $(136)$ & Surrey, traffic related, 1993-1999 \\
\hline Stevenson, 2001 & $(137)$ & Urban UK, 1993-1997, 1000 sites \\
\hline Loader, 2001 & $(87)$ & UK Network data for 2000 \\
\hline Kirby, 2001 & $(21)$ & Cambridge, Norwich and London \\
\hline Hickman, 2002 & $(112)$ & Motorway (M25), 1998-2001 \\
\hline Loader, 2003 & $(85)$ & UK Network data for 2001 \\
\hline Stevenson, 2003 & $(113)$ & Heathrow Airport, spatial \\
\hline Cape, 2004 & $(94)$ & Scotland, roadside, 14 sites, membrane \\
\hline Marner, 2004 & $(77)$ & West Midlands, 10 sites, 1999-2001 \\
\hline Loader, 2004 & $(71)$ & UK Network data for 2002 \\
\hline Barnes, 2005 & $(138)$ & Cornwall, urban, 11 towns \\
\hline \multicolumn{3}{|r|}{ Other countries } \\
\hline Noy, 1990 & $(139)$ & $\begin{array}{l}\text { Personal \& indoors; conditional sampling of } \\
\text { 'peak' conditions }\end{array}$ \\
\hline
\end{tabular}


Published in Crit Rev Anal Chem 39(4), 289-310, 2009

\begin{tabular}{|l|c|l|}
\hline Madany, 1993 & $(140)$ & Bahrain, 1992, 55 sites \\
\hline Haue-Pedersen, 1993 & $(66)$ & Odense, Denmark; urban \\
\hline della Massa, 1994 & $(141)$ & Toulouse, France, spatial \\
\hline Moriske, 1996 & $(29)$ & Berlin, roadside \\
\hline Shooter, 1997 & $(15)$ & Rural and urban New Zealand \\
\hline Krochmal, 1997 & $(142)$ & Urban \& rural Poland; short path sampler, 147 sites \\
\hline Perkauskas, 1998 & $(93)$ & Vilnius, Lithuania; urban \\
\hline Roorda-Knape, 1998 & $(143)$ & Netherlands, urban, motorway \\
\hline Marcoux, 1998 & $(144)$ & Spatial - Alpine valley, France \\
\hline Glasius, 1999 & $(64)$ & Funen, Denmark, 43 sites \\
\hline Hansen, 2001 & $(43)$ & Greenland, 43 sites \\
\hline Sanz, 2001 & $(145)$ & European Forest Health Monitoring, 230 plots \\
\hline Gonzales, 2005 & $(34)$ & Urban, US-Mexico border \\
\hline Baumbach, 2006 & $(146)$ & Cyprus, 250 sites over one year \\
\hline da Silva, 2006 & $(147)$ & Sao Paolo, Brazil; urban, traffic related, 33 sites \\
\hline
\end{tabular}


Published in Crit Rev Anal Chem 39(4), 289-310, 2009

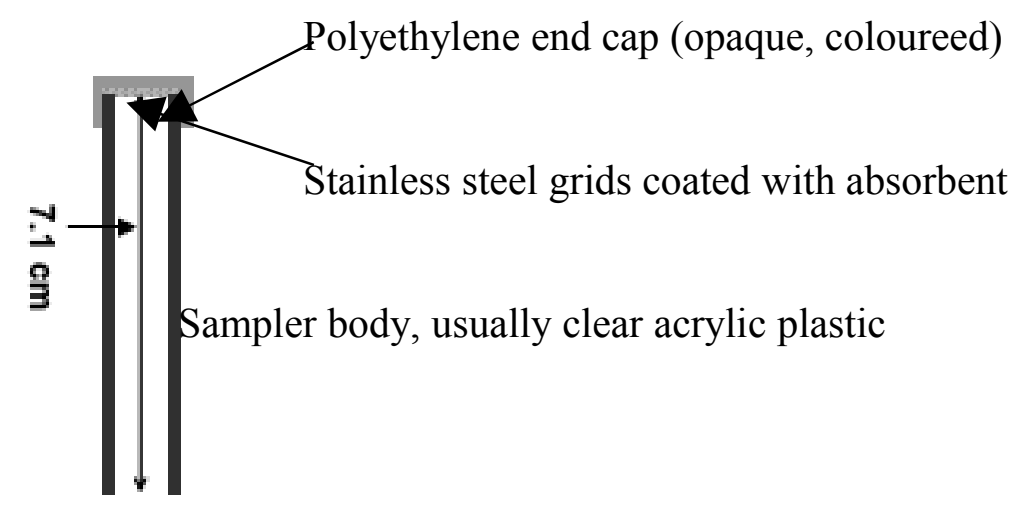

Figure 1: diagram of Palmes-type diffusion sampler 
Published in Crit Rev Anal Chem 39(4), 289-310, 2009

Gerboles et al., 2005

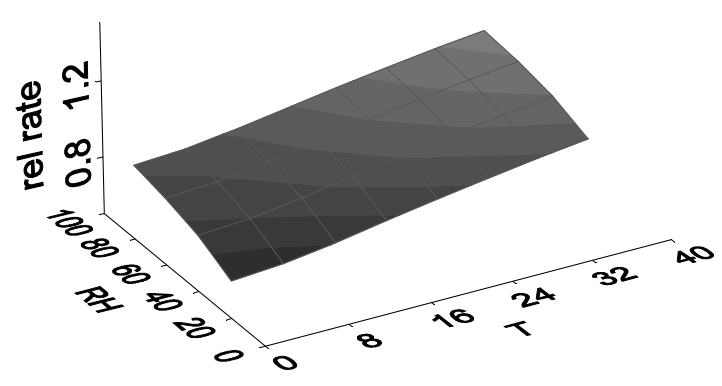

Buzica et al., 2005

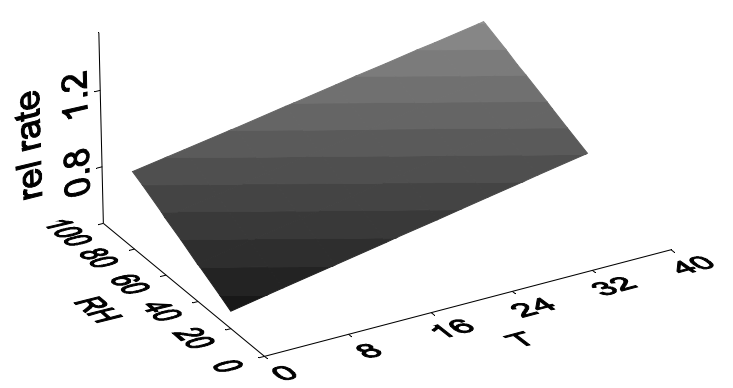

Figure 2. Variation of sampling rate with temperature $\left(\mathrm{T},{ }^{\circ} \mathrm{C}\right)$ and relative humidity (RH, \%) based on dependence on $\left[\mathrm{H}_{2} \mathrm{O}\right]$ (Gerboles et al., 2005) ${ }^{51}$ - on left) or $\mathrm{T}$ and $\mathrm{RH}$ (Buzica et al., $2005{ }^{27}-$ on right). Data are expressed relative to calculated rates at $1 \mathrm{~m}$ $\mathrm{s}^{-1}, 20{ }^{\circ} \mathrm{C}$ and $60 \% \mathrm{RH}$ so that they can be compared visually. 


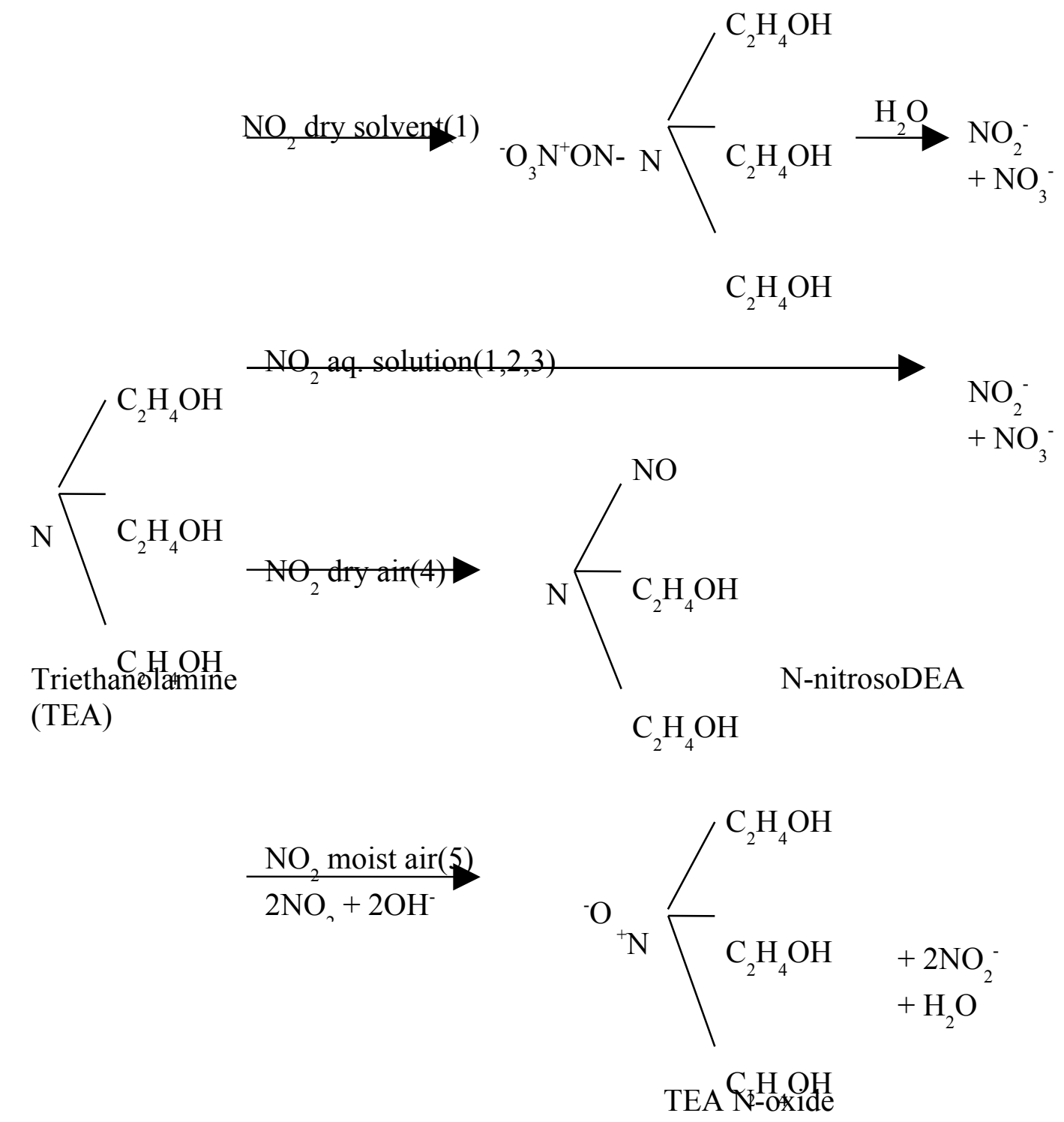

Figure 3. Schematic of possible reactions of TEA with $\mathrm{NO}_{2}$ with different products depending on conditions of reaction. Specific references are:

1) Gold, 1977 (57)

2) Li et al., 1999 (63)

3) Wei et al., 2002 (65)

4) Aoyama and Yashiro, 1983 (62); Brown, 1993 (2)

5) Glasius et al., 1999 (64) 
Published in Crit Rev Anal Chem 39(4), 289-310, 2009

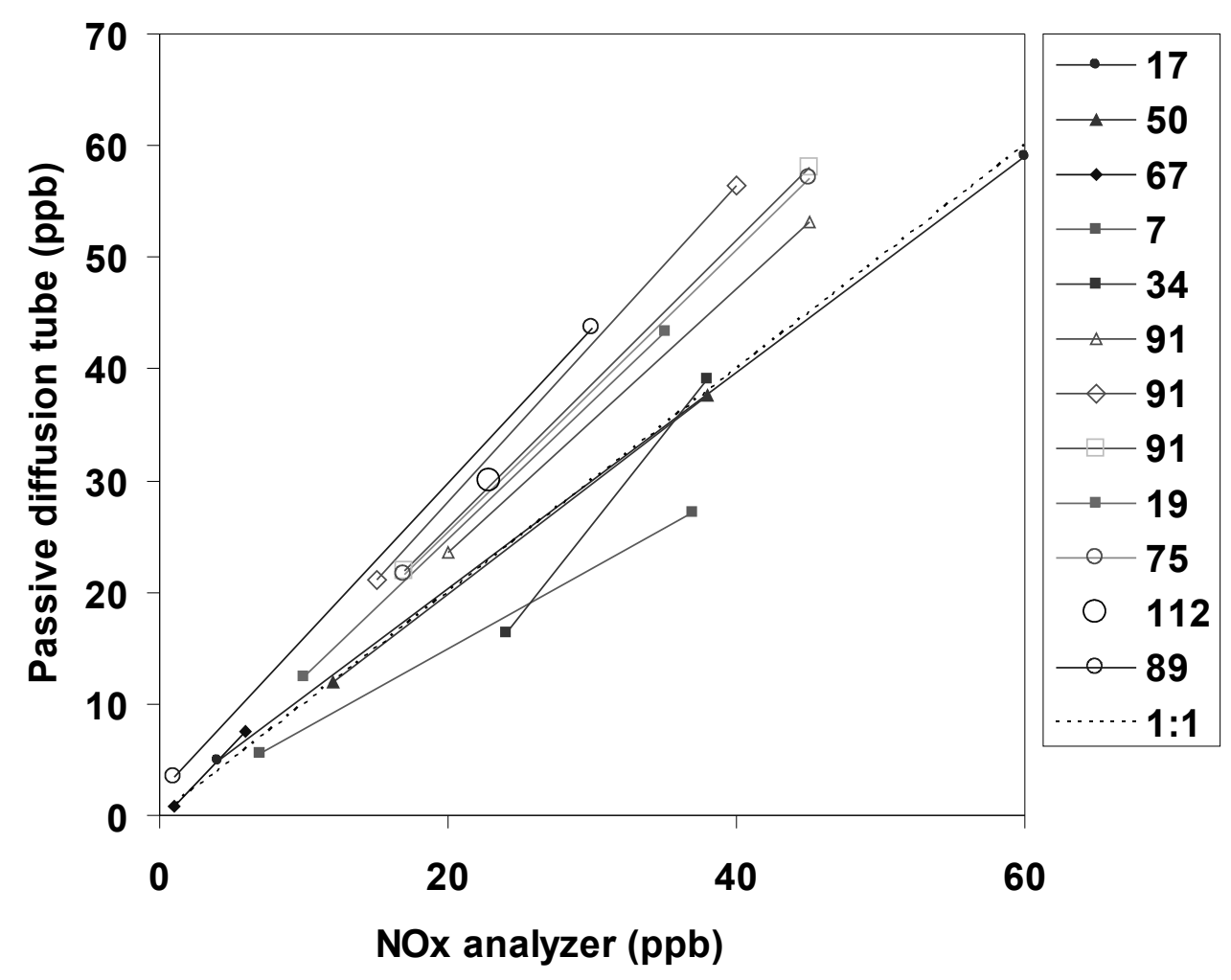

Figure 4. Field comparisons of $\mathrm{NO}_{2}$ concentrations measured using passive diffusion tubes exposed for 1 week with concentrations from a chemiluminescent NO analyzer (Table 4). 


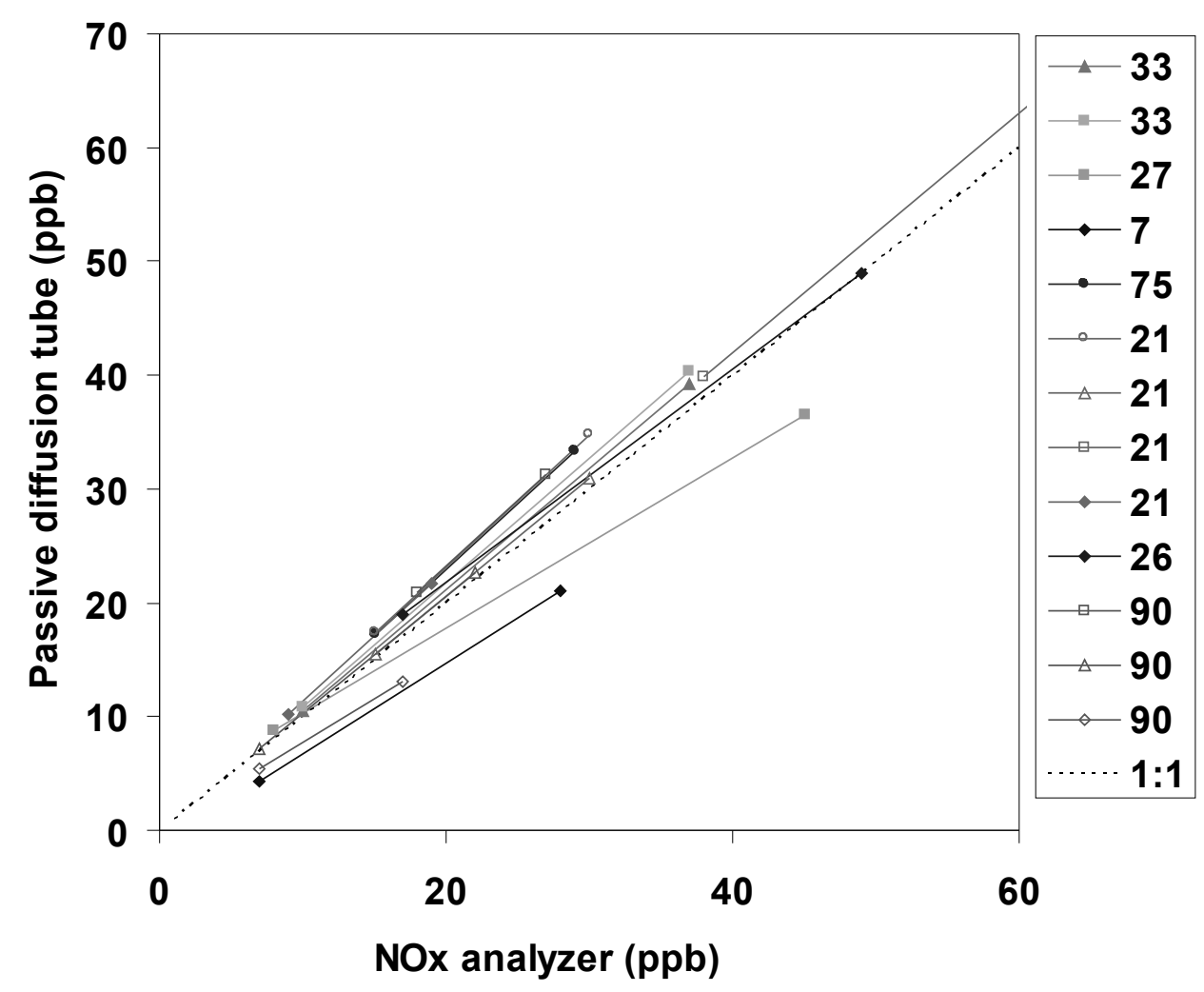

Figure 5. Field comparisons of $\mathrm{NO}_{2}$ concentrations measured using passive diffusion tubes exposed for 2 weeks with concentrations from a chemiluminescent $\mathrm{NO}_{\mathrm{x}}$ analyzer (Table 5). 


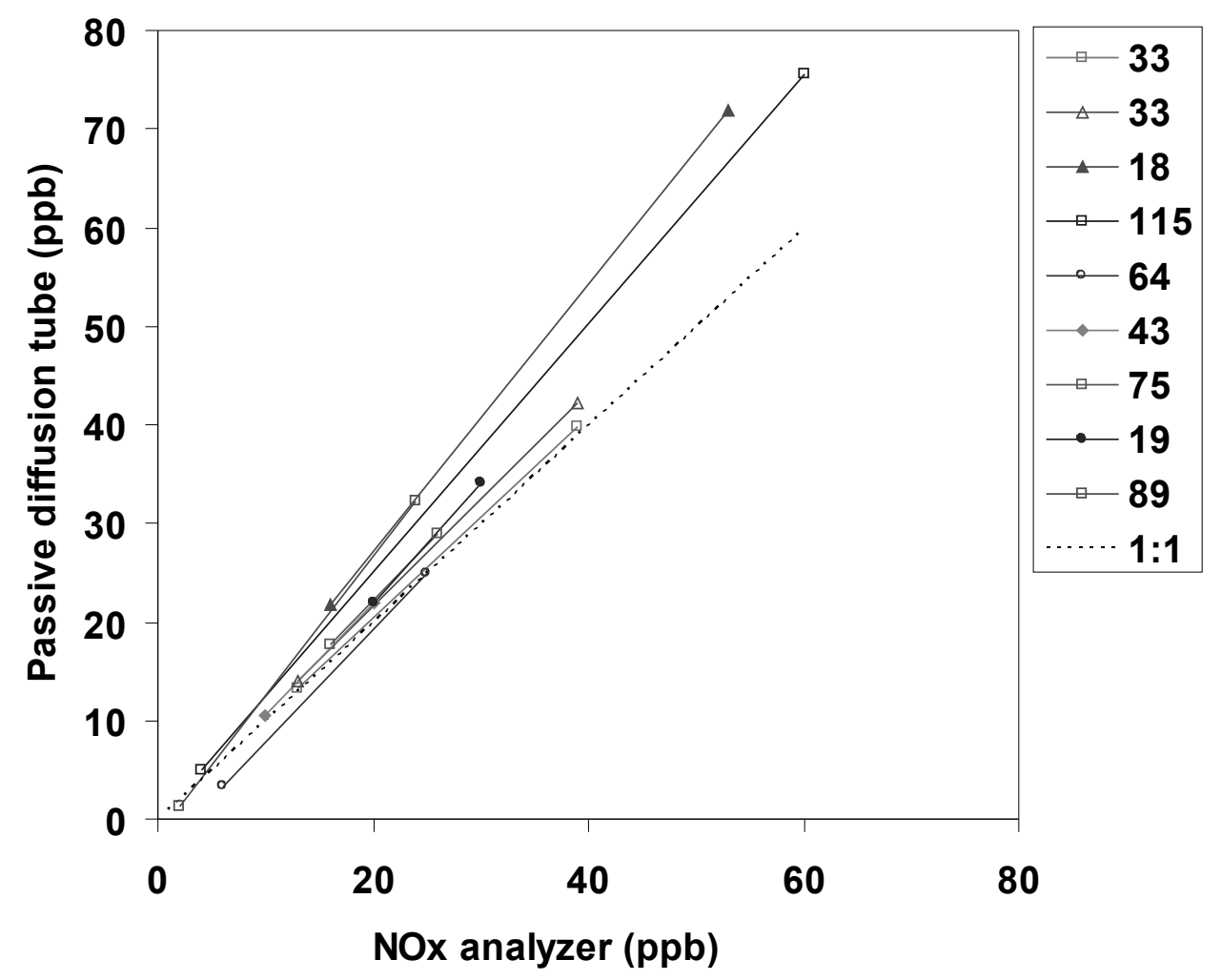

Figure 6. Field comparisons of $\mathrm{NO}_{2}$ concentrations measured using passive diffusion tubes exposed for 4 weeks with concentrations from a chemiluminescent $\mathrm{NO}_{\mathrm{x}}$ analyzer (Table 6). 